\title{
Theoretical prediction from classical equations and rational synthesis of ultra-fine LTL zeolite nanocrystals
}

Fen Zhang, ${ }^{\dagger}, \#$ Wei Chen, ${ }^{\S}$ Qinming Wu, ${ }^{\dagger}$ Zhichao Yang, ${ }^{\$}$ Liang Wang, ${ }^{\dagger}$ Xiangju Meng, ${ }^{* \dagger}$ Bingsen Zhang, ${ }^{*} \star$ Anmin Zheng, ${ }^{\S}$ Feng Deng, ${ }^{\S}$ Chenguang Liu, ${ }^{\S}$ and Feng-Shou Xiao*,†

$\dagger$ Department of Chemistry, Key Lab of Applied Chemistry of Zhejiang Province, Zhejiang University, Hangzhou, 310028, P. R. China

\# Institute of Applied Chemistry, Jiangxi Academy of Sciences, Nanchang, 330096, P.

R. China

${ }^{\star}$ Catalysis and Materials Division, Shenyang National Laboratory for Materials Science, Institute of Metal Research, Chinese Academy of Sciences, Shenyang, 110016, P. R. China

$\S$ State Key Laboratory of Magnetic Resonance and Atomic and Molecular Physics, National Center for Magnetic Resonance, Wuhan Institute of Physics and Mathematics, Chinese Academy of Sciences, Wuhan, 430071, P. R. China

\$ State Key Laboratory of Heavy Oil Processing, Key Laboratory of Catalysis, China National Petroleum Corp. (CNPC), China University of Petroleum (East China), Qingdao, 266580, P. R. China 


\section{Theoretical Section}

\section{Theoretical prediction from classical equations}

Kaptay showed the revised form in the following:

$$
r=\frac{2 \Omega \sigma}{k T \ln \frac{\Delta C}{C_{o}}}
$$

where $r$ is the crystal radius, $\Omega$ is cell volume of the liquid, $\sigma$ is the surface free energy, $k$ is Boltzmann constant, $T$ is absolute temperature $(\mathrm{K}), \Delta C$ is degree of supersaturation, and $C_{o}$ is the equilibrium concentration.

In order to derive the value of the $\frac{\Delta C}{C_{0}}$, other classical equations to describe the crystal growth, proposed by Brice half century ago, would be employed and revised as shown in the following:

$$
\begin{aligned}
& v=\lambda \frac{k}{h R} \Delta G_{v} \exp \left(\frac{-\Delta \emptyset+\Delta \emptyset_{1}}{R T}\right) \\
& \Delta G_{v}=\operatorname{aRT} \ln \left(1+\frac{\Delta C}{C_{o}}\right)=a R T \frac{\Delta C}{C_{o}}
\end{aligned}
$$

where $\Delta G_{v}$ is the free energy difference between the solid and the supersaturated liquid, $v$ is the crystal linear growth rate, $h$ is Planck constant, $k$ is Boltzmann constant, $\lambda$ is the intermolecular spacing, $R$ is the gas constant and $\Delta \phi, \Delta \phi_{1}$ are the free energies per molecule.

After coupling equation (I), (II), and (III), new equation would be obtained as shown:

$$
\frac{1}{r}=\frac{k T}{2 \Omega \sigma} \ln v+\frac{\frac{k}{R}\left(\Delta \emptyset-\Delta \emptyset_{1}\right)-k T \ln \frac{a \lambda k T}{h}}{2 \Omega \sigma}
$$

Considering the cell volume of the liquid and surface free energy would be constants at the fixed temperature, the above equation could be presented in a simple form:

$$
\frac{1}{r}=m \ln v+n
$$

\section{Calculation of the $m$ and $\boldsymbol{n}$ in equation ( $V$ ) in synthesis of zeolite $L$}

Considering the parameters $\left(\Omega=2.153 * 10^{-27} \mathrm{~m}^{3}, k=1.38 * 10^{-23}, T=353 \mathrm{~K}\right)$ have been fixed, the value of $m$ is related to $\sigma$ of zeolite $\mathrm{L}$. 
All DFT calculations in this study were employed by VASP code ${ }^{1}$, the exchange-correlation energy was described by the PBE functional ${ }^{2,3}$ with Grimme's dispersion correction (DFT-D3) ${ }^{4}$. The Brillouin-zone sampling was restricted to the $\Gamma$ point. The electron-ion interaction was solved by the projector augmented wave (PAW) method, and the iterative solutions of Kohn-Sham equations was done using a plane-wave basis set with a cutoff energy of $550 \mathrm{eV}$. The convergence criterion for the electronic self-consistency cycle and force was set to $10^{-5} \mathrm{eV}$ and $0.01 \mathrm{eV} / \AA$. To obtain the surface free energy, the TAMkin software ${ }^{5}$ was employed to calculate the Gibbs free energy based on frequency calculation of optimized bulk and slab structures. The surface free energy $\sigma$ is defined as follow: ${ }^{6}$

$$
\sigma=\left(\mathrm{G}_{\text {slab }}-\mathrm{G}_{\text {bulk }}-q \mathrm{G}_{\text {water }}\right) / 2 \mathrm{~A}
$$

where $A$ is the surface area, $G_{\text {slab }}, G_{b u l k}$, and $G_{w a t e r}$ is the Gibbs free energy of slab, bulk, and water at $353 \mathrm{~K}, q$ is the number of water molecules added to terminate the slab structure.

Using DFT calculations above, the value of $\sigma$ is calculated at $0.084 \mathrm{~J} / \mathrm{m}^{2}$, then giving $m=1.38^{*} 10^{7}$.

Considering $\Delta \phi$ is nearly the same as $\Delta \phi_{1}$, the value of $\alpha$ is 1 , so the value of $n$ is related to $\lambda$ of zeolite $\mathrm{L}$. To obtain the intermolecular spacing of Si (or Al) units in solution, we build a box to estimation. Firstly, we assumed that the Si (or Al) units are completely uniform dispersed in solution, and the intermolecular spacing among all $\mathrm{Si}$ units are the same.

The number of $\mathrm{Si}$ (or Al) in unit volume is as follows:

$$
\mathrm{N}_{\mathrm{b}}=\left(\mathrm{n}_{\mathrm{Al}}+\mathrm{n}_{\mathrm{Si}}\right) * \mathrm{~N}_{\mathrm{A}} / \mathrm{V}_{\mathrm{s}}
$$

where $\mathrm{n}_{\mathrm{Al}}$ and $\mathrm{n}_{\mathrm{Si}}$ are the molar quantity of $\mathrm{Si}$ (or $\mathrm{Al}$ ) units in solution, $\mathrm{V}_{\mathrm{s}}$ is the volume of solution, $\mathrm{N}_{\mathrm{A}}$ is the Avogadro's constant. Here, the Si (or Al) units were defined as a unit containing one $\mathrm{Si}$ (or $\mathrm{Al}$ ) atom.

If the radii of $\mathrm{Si}$ (or Al) units is $\mathrm{r}$ (including the gap between units), then the unit volume of the box is in the following:

$$
\mathrm{V}_{\mathrm{box}}=2 \mathrm{ra}^{*} 2 \mathrm{rb}^{*} 2 \mathrm{rc}=8 \mathrm{r}^{3} \mathrm{abc}=1
$$


Here, $\mathrm{a}, \mathrm{b}$ and $\mathrm{c}$ are the number of $\mathrm{Si}$ (or $\mathrm{Al}$ ) units in three sides of the box, and $a^{*} b^{*} \mathrm{c}=\mathrm{N}_{\mathrm{b}}$.

According to these calculated results, the value of $\lambda$ is $3.3 * 10^{-5} \mathrm{~m}$, then giving $n=-2.6^{*} 10^{8}$.

\section{Calculation of the $\ln v$ in equation $(V)$ in synthesis of zeolite $L$.}

We could get the value of $\ln v$ from the crystallization process of zeolite L. Here, we define the value of $v$ as shown as following:

$$
v=\frac{L}{t}
$$

$L$ stands for length of zeolite crystal, while the $t$ stands for the growth time of the crystallization process.

Here, the $v$ stands for the growth rate along [100] direction of zeolite L for example, the growth rate of Nano L-30 in experiment is shown in the following:

$$
v_{[100]}=\frac{30 * 10^{-9}}{72-12}=5 * 10^{-10} \mathrm{~m} / \mathrm{h}
$$




\section{Experimental Section}

1. Materials

Sodium aluminate $\left(\mathrm{NaAlO}_{2}, \quad 36.6 \% \quad \mathrm{Na}_{2} \mathrm{O}\right.$ and $43.3 \% \quad \mathrm{Al}_{2} \mathrm{O}_{3}$, Sinopharm Chemical Reagent Co., Ltd.), sodium hydroxide (NaOH, AR, 96\%, Sinopharm Chemical Reagent Co., Ltd.), potassium hydroxide (KOH, AR, 85\%, Sinopharm Chemical Reagent Co., Ltd.), silica sol (LUDOX HS-40, $40 \% \mathrm{SiO}_{2}$ in water, Sigma Aldrich), aluminum sulfate $\left[\mathrm{Al}_{2}\left(\mathrm{SO}_{4}\right)_{3} \cdot 18 \mathrm{H}_{2} \mathrm{O}, \mathrm{AR}, 99 \%\right.$, Sinopharm Chemical Reagent Co., Ltd.], sodium silicate solution $\left(253.8 \mathrm{~g} / \mathrm{L} \mathrm{SiO}_{2}, 77.8 \mathrm{~g} / \mathrm{L} \mathrm{Na} \mathrm{Na}_{2} \mathrm{O}\right.$ of $1 \mathrm{~L}$ sodium silicate solution), tetrapropylammonium hydroxide (TPAOH, 40\% TPAOH in water, Aladdin), tetraethylorthosilicate (TEOS, 99\%, Aladdin), urea (AR, 99\%, Aladdin), ammonium nitrate $\left(\mathrm{NH}_{4} \mathrm{NO}_{3}, \mathrm{AR}, 99 \%\right.$, Beijing Chemical Reagent Co., Ltd.), and $\mathrm{Pt}\left(\mathrm{NH}_{2}\right)_{4} \mathrm{Cl}_{2}(98 \%)$ were used without further purification. The deionized water was made in our laboratory.

\section{Synthesis of zeolite L precursors}

As a typical run, zeolite L precursor was prepared by mixing $10 \mathrm{~mL}$ deionized $\mathrm{H}_{2} \mathrm{O}, 0.472 \mathrm{~g}$ sodium aluminate and $3.76 \mathrm{~g}$ potassium hydroxide under stirring for 10 mins, followed by addition of $8.4 \mathrm{~g}$ silica sol. After stirring for $1 \mathrm{~h}, 0.24 \mathrm{~g}$ sodium hydroxide was finally added, followed by aging at room temperature for $72 \mathrm{~h}$, giving a clear solution. The molar ratios of the precursors are $3.0 \mathrm{Na}_{2} \mathrm{O} / 14.3 \mathrm{~K}_{2} \mathrm{O} / \mathrm{Al}_{2} \mathrm{O}_{3} / 28 \mathrm{SiO}_{2} / 413 \mathrm{H}_{2} \mathrm{O}$, was designed as $\mathrm{L}$ precursor-1. The precursors-2, $-3,-4$ and -5 synthesized at the same conditions except for the decrease amount of potassium hydroxide to $3.6 \mathrm{~g}, 3.4 \mathrm{~g}, 3.2 \mathrm{~g}$ and $3.0 \mathrm{~g}$, respectively.

\section{Synthesis of zeolite L nanocrystals}

Zeolite L nanocrystals were hydrothermally synthesized at the temperature of 80 ${ }^{\circ} \mathrm{C}$ for 3 days with $2.1 \mathrm{Na}_{2} \mathrm{O} / 2.9 \mathrm{~K}_{2} \mathrm{O} / \mathrm{Al}_{2} \mathrm{O}_{3} / 15 \mathrm{SiO}_{2} / 250 \mathrm{H}_{2} \mathrm{O}$ molar ratios of starting gels in the presence of zeolite L precursors. For the preparation of starting gel, we dissolved $0.99 \mathrm{~g}$ potassium hydroxide into $8.9 \mathrm{~mL}$ sodium silicate solution, followed by introducing $1.4 \mathrm{~g}$ deionized $\mathrm{H}_{2} \mathrm{O}$. After the solution was stirred for about $1 \mathrm{~h}, 1.665$ g aluminum sulfate was added into the mixture, followed by the addition of $2.0 \mathrm{~mL}$ zeolite L precursor-X $(\mathrm{X}=1,2,3,4,5)$. After being stirred for $2 \mathrm{~h}$ at room temperature, the mixture was transferred into an autoclave to crystallize at $80{ }^{\circ} \mathrm{C}$ for 3 days. The 
products were collected by filtration, washed with deionized $\mathrm{H}_{2} \mathrm{O}$, and dried in air, respectively. The $\mathrm{H}$-form of the samples was prepared by triple ion-exchange with $1 \mathrm{M}$ of $\mathrm{NH}_{4} \mathrm{NO}_{3}$ solution at $80{ }^{\circ} \mathrm{C}$ for $1 \mathrm{~h}$ and calcination at $550{ }^{\circ} \mathrm{C}$ for $5 \mathrm{~h}$. The $\mathrm{H}$-form $\mathrm{L}$ samples were denoted as Nano L-20, Nano L-30, Nano L-40, Nano L-60 and Nano L-100 according to the distance of [100] direction determined from HRTEM pictures.

4. Synthesis of conventional zeolite L

Conventional zeolite L crystal was hydrothermally synthesized at the temperature of $180{ }^{\circ} \mathrm{C}$ for 1 day with $3.73 \mathrm{~K}_{2} \mathrm{O} / \mathrm{Al}_{2} \mathrm{O}_{3} / 12.5 \mathrm{SiO}_{2} / 150 \mathrm{H}_{2} \mathrm{O}$ molar ratios of starting gels. The product was collected by filtration, washed with deionized $\mathrm{H}_{2} \mathrm{O}$, and dried in air. The $\mathrm{H}$-form of the sample was prepared by triple ion-exchange with $1 \mathrm{M}$ of $\mathrm{NH}_{4} \mathrm{NO}_{3}$ solution at $80{ }^{\circ} \mathrm{C}$ for $1 \mathrm{~h}$ and calcination at $550{ }^{\circ} \mathrm{C}$ for $5 \mathrm{~h}$, designated conventional bulky L.

\section{Synthesis of MFI zeolite crystals}

MFI zeolite crystals were hydrothermally synthesized at the temperature of 200 ${ }^{\circ} \mathrm{C}$ for 2 days with molar ratio of $\mathrm{SiO}_{2} / 0.29 \sim 0.95 \mathrm{TPAOH} / 30 \mathrm{H}_{2} \mathrm{O} / 0.806$ urea in the starting gels. For the preparation of starting gel, we dissolved 2.0-6.5 g TPAOH solution into 5.2-3.4 g deionized $\mathrm{H}_{2} \mathrm{O}$, followed by introducing $2.8 \mathrm{~g}$ TEOS. After stirring for $4 \mathrm{~h}, 0.65 \mathrm{~g}$ urea was added into the mixture. stirring for another $2 \mathrm{~h}$ at room temperature, the mixture was transferred into an autoclave to crystallize at 200 ${ }^{\circ} \mathrm{C}$ for $2 \mathrm{~d}$ days. The products were collected by filtration, washed with deionized $\mathrm{H}_{2} \mathrm{O}$, and dried in air, respectively.

\section{Catalyst preparation and catalytic tests}

Pt (0.5 wt.\%) was loaded on the Nano L-20, Nano L-100 and conventional bulky L samples by wet impregnation method using $\mathrm{Pt}\left(\mathrm{NH}_{3}\right)_{4} \mathrm{Cl}_{2}$ as a $\mathrm{Pt}$ source, followed by drying at $120{ }^{\circ} \mathrm{C}$ for overnight and calcined at $450{ }^{\circ} \mathrm{C}$ for $3 \mathrm{~h}$. The obtained samples were pressed into tablets with a diameter of $12.7 \mathrm{~mm}$, using a hand-operated press for 10 min. Then, the as-prepared tablets were crushed into particles with $20-40$ mesh sizes, which were designated as Pt/Nano L-20, Pt/Nano L-100 and Pt/Conventional bulky L, respectively.

The $n$-dodecane $\left(n-\mathrm{C}_{12}\right)$ hydroisomerization was carried out on a stainless steel 
continuous flow fixed-bed microreactor ( $10.5 \mathrm{~mm}$ inner diameter). The catalysts were tested at $260-340{ }^{\circ} \mathrm{C}, 1.0 \mathrm{MPa}, \mathrm{H}_{2} / n$-dodecane (V/V) ratio of 400 , and weight hourly space velocity (WHSV) at $1.5 \mathrm{~h}^{-1}$. The catalysts were sieved 20-40 mesh size and loaded in the middle of the reactor. Both sides of the reactor were filled with quartz sand with the same mesh size to the catalysts. Before the assessment, $2.0 \mathrm{~g}$ of catalysts was reduced in situ with a $\mathrm{H}_{2}$ flow of $25 \mathrm{~cm}^{3} / \mathrm{min}$ at $400{ }^{\circ} \mathrm{C}$ for $2 \mathrm{~h}$. After reduction, the reactor temperature cooled to the reaction temperature, $n$-dodecane was fed into the reactor by a metering pump. When the specified reaction conditions were achieved, the products were obtained and analyzed by a gas chromatograph, equipped with a flame ionization detector and a capillary column.

\section{Characterization}

Powder X-ray diffraction (XRD) data were collected with a Rigaku Ultimate VI $\mathrm{X}$-ray diffractometer $(40 \mathrm{kV}, 40 \mathrm{~mA})$ using $\mathrm{CuK} \alpha_{1}$ radiation $(\lambda=1.5406 \AA)$ using a flat plate sample holder. Scanning electron microscopy (SEM) studies were performed on Hitachi SU-1510 and SU-8010 electron microscopes. High-resolution transmission electron micrograph (HRTEM) pictures were performed on Hitachi HT-7700 electron microscope. $\mathrm{N}_{2}$ sorption experiments were performed on a Micromeritics TriStar II at $-196{ }^{\circ} \mathrm{C}$. The pore volume and surface area were calculated from using the $t$-plot and BET methods. The sample composition was determined by Perkin-Elmer inductively coupled plasma optical emission spectrometer (ICP-OES) optima 8000. Dynamic light scattering (DLS) experiments were performed using a Malvern Instrument Zetasizer Nano ZS90. ${ }^{27} \mathrm{Al}$ and ${ }^{29} \mathrm{Si}$ solid-state NMR spectra were recorded on a Varian Infinity Plus 400 spectrometer. 
Table S1 The growth rate $(v)$ along [100] direction of zeolite L nanocrystals

\begin{tabular}{cccc}
\hline Sample & Nano L-30 & Nano L-40 & Nano L-60 \\
\hline$v(\mathrm{~m} / \mathrm{h})$ & $5 * 10^{-10}$ & $6.67 * 10^{-10}$ & $1 * 10^{-9}$ \\
$\ln v$ & -21.42 & -21.13 & -20.72 \\
\hline
\end{tabular}

Table S2 Textural parameters for the series of $\mathrm{H}$-form zeolite L nanocrystals

\begin{tabular}{ccccccc}
\hline Sample & $\begin{array}{c}\boldsymbol{S}_{\text {BET }} \\
\left(\mathbf{m}^{2} / \mathbf{g}\right)\end{array}$ & $\begin{array}{c}\boldsymbol{S}_{\text {micro }} \\
(\mathbf{m} / \mathbf{g})\end{array}$ & $\begin{array}{c}\boldsymbol{S}_{\text {meso }} \\
(\mathbf{m} / \mathbf{g})\end{array}$ & $\begin{array}{c}\boldsymbol{V}_{\text {total }} \\
\mathbf{( \mathbf { c m } ^ { 3 } / \mathbf { g } )}\end{array}$ & $\begin{array}{c}\boldsymbol{V}_{\text {micro }} \\
\mathbf{( \mathbf { c m } ^ { 3 } / \mathbf { g } )}\end{array}$ & $\begin{array}{c}\boldsymbol{V}_{\text {meso }} \\
\left(\mathbf{c m}^{\mathbf{3}} / \mathbf{g}\right)\end{array}$ \\
\hline Nano L-20 & 332 & 264 & 68 & 0.46 & 0.12 & 0.34 \\
Nano L-30 & 316 & 226 & 90 & 0.46 & 0.11 & 0.35 \\
Nano L-40 & 320 & 232 & 88 & 0.46 & 0.12 & 0.36 \\
Nano L-60 & 314 & 220 & 94 & 0.45 & 0.10 & 0.35 \\
Nano L-100 & 251 & 197 & 54 & 0.37 & 0.09 & 0.28 \\
Conventional L & 146 & 132 & 14 & 0.19 & 0.11 & 0.08 \\
\hline
\end{tabular}


Figure S1. XRD patterns of Nano L-30 sample crystallized after (a) 6, (b) 12, (c) 24, (d) 27, (e) 30, (f) 36, (g) 48 h, and (h) $72 \mathrm{~h}$, respectively.

Figure S2. XRD patterns of Nano L-40 sample crystallized after (a) 6, (b) 12, (c) 24, (d) 27, (e) 30, (f) 36, (g) 48 h, and (h) 72 h, respectively.

Figure S3. XRD patterns of Nano L-60 sample crystallized after (a) 6, (b) 12, (c) 24, (d) 27, (e) 30, (f) 36, (g) $48 \mathrm{~h}$, and (h) $72 \mathrm{~h}$, respectively.

Figure S4. HRTEM images of as-synthesized Nano L-30 sample.

Figure S5. HRTEM images of as-synthesized Nano L-40 sample.

Figure S6. HRTEM images of as-synthesized Nano L-60 sample.

Figure S7. The distance distribution of (a) [100] direction and (b) [001] direction of Nano L-60 sample.

Figure S8. The distance distribution of (a) [100] direction and (b) [001] direction of Nano L-40 sample.

Figure S9. The distance distribution of (a) [100] direction and (b) [001] direction of Nano L-30 sample.

Figure S10. XRD pattern of as-synthesized conventional bulky L sample.

Figure S11. $\mathrm{N}_{2}$ sorption isotherms of H-form conventional bulky L sample.

Figure S12. HRTEM images of as-synthesized Nano L-20 sample.

Figure S13. The distance distribution of (a) [100] direction and (b) [001] direction of Nano L-20 sample.

Figure S14. ${ }^{29}$ Si MAS NMR spectra of as-synthesized conventional bulky L sample.

Figure S15. XRD pattern of as-synthesized Nano L-100 sample.

Figure S16. $\mathrm{N}_{2}$ sorption isotherm of H-form Nano L-100 sample. 
Figure S17. HRTEM images of as-synthesized Nano L-100 sample.

Figure S18. The distance distribution of (a) [100] direction and (b) [001] direction of Nano L-100 sample.

Figure S19. DLS curve of as-synthesized Nano L-100 sample.

Figure S20. ${ }^{29}$ Si MAS NMR of as-synthesized Nano L-100 sample.

Figure S21. HRTEM images and Pt size distribution of Pt/Nano L-20 catalyst (A) before reaction and $(\mathrm{B})$ after reaction.

Figure S22. HRTEM images and Pt size distribution of Pt/Nano L-100 catalyst (A) before reaction and $(\mathrm{B})$ after reaction.

Figure S23. HRTEM images and Pt size distribution of $\mathrm{Pt} /$ Conventional bulky L catalyst (A) before reaction and (B) after reaction.

Figure S24. SEM images of MFI zeolite crystals with $\mathrm{TPAOH} / \mathrm{SiO}_{2}$ at (a) 0.95 , (b) 0.88 , (c) 0.81 , (d) 0.73 , and (e) 0.65 under the guidance of theoretical prediction.

Figure S25. (A) Theoretical crystallization rates of MFI zeolite calculated from equation, (B) dependence of $\ln v$ on the ratio of $\mathrm{TPAOH} / \mathrm{SiO}_{2}$ in the starting gels. 


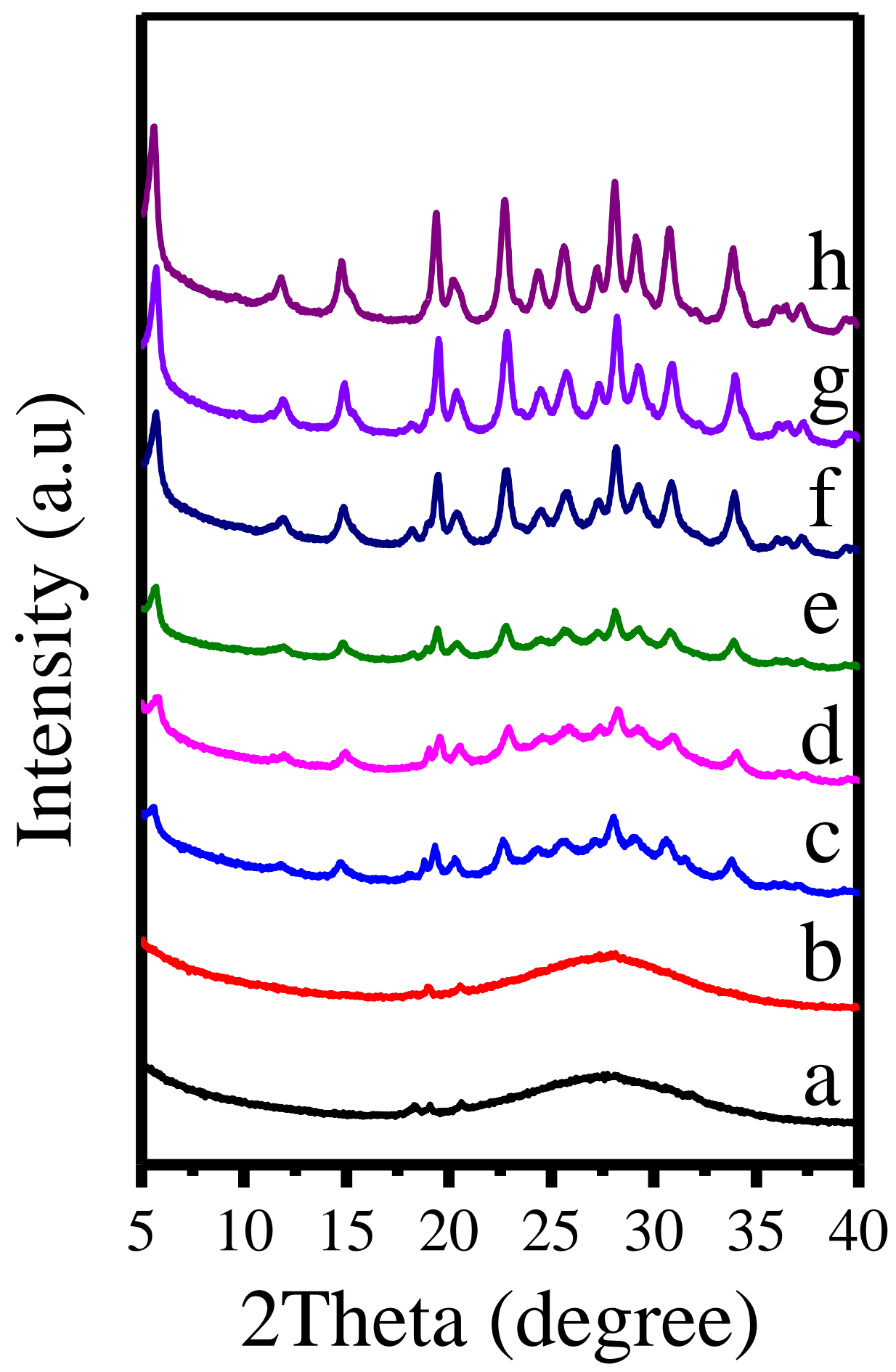

Figure S1. XRD patterns of Nano L-30 sample crystallized after (a) 6, (b) 12, (c) 24, (d) 27, (e) 30, (f) 36, (g) 48 h, (h) 72 h, respectively. 


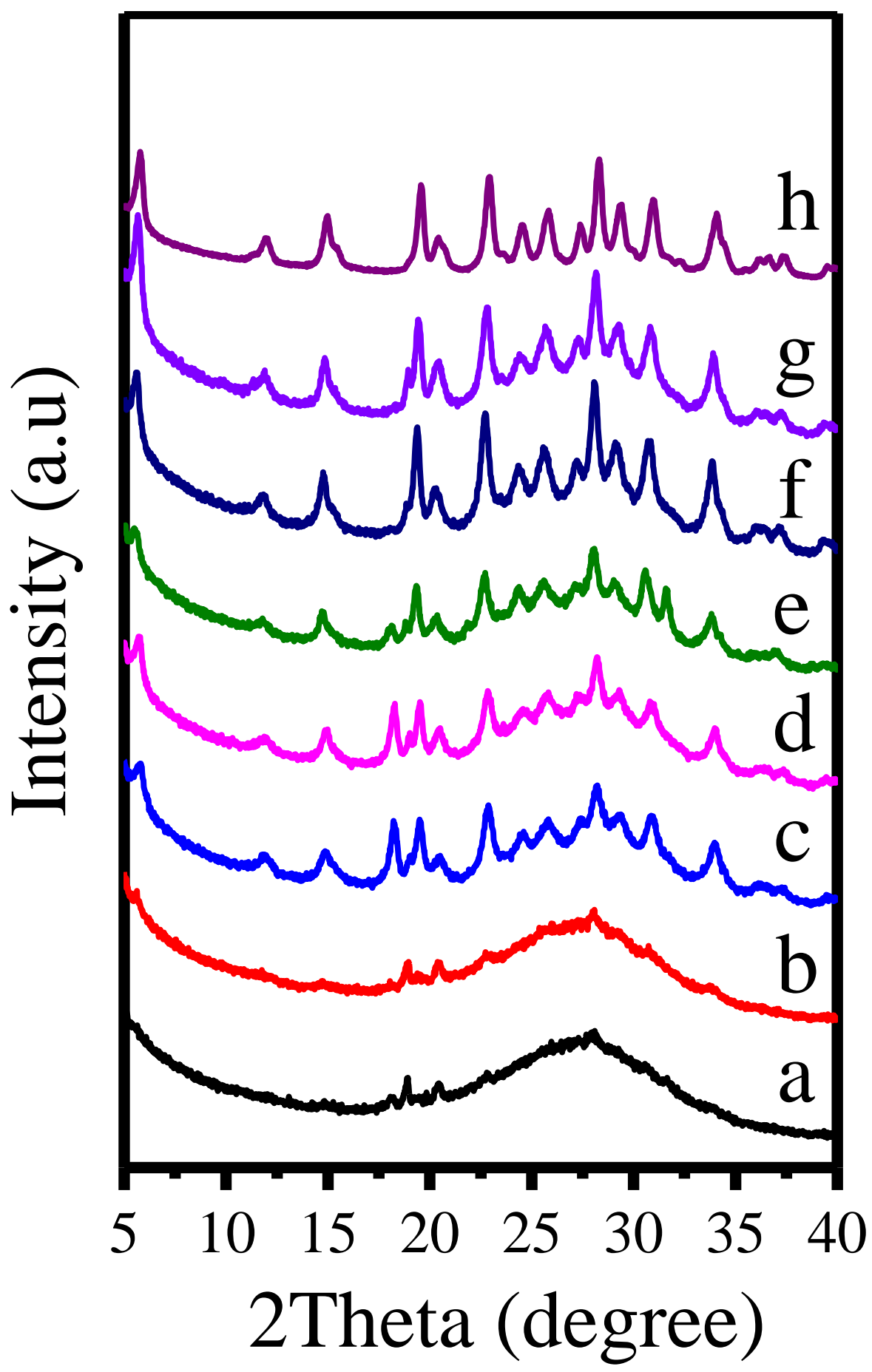

Figure S2. XRD patterns of Nano L-40 sample crystallized after (a) 6, (b) 12, (c) 24, (d) 27, (e) 30, (f) 36, (g) 48 h, (h) $72 \mathrm{~h}$, respectively. 


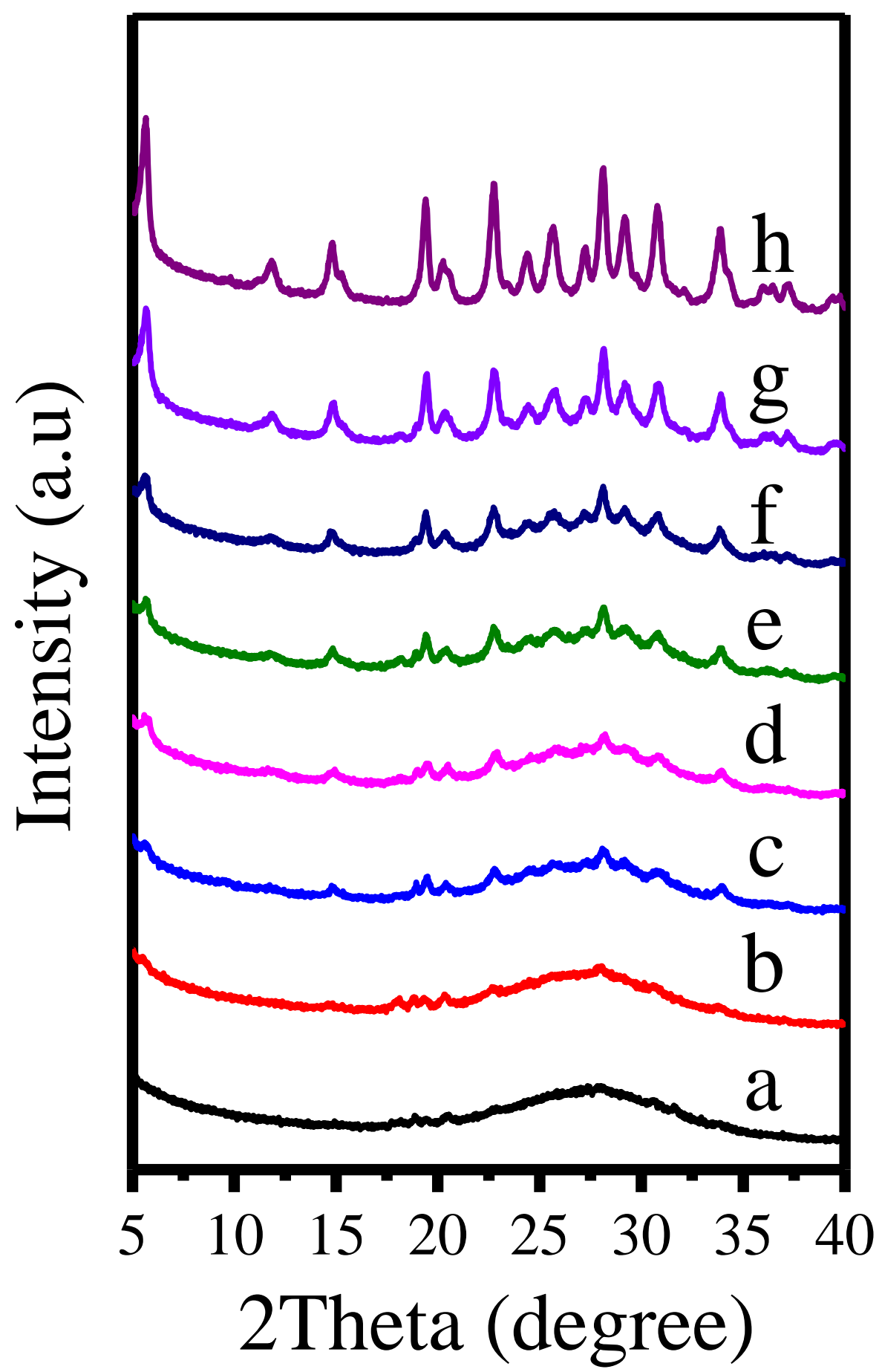

Figure S3. XRD patterns of Nano L-60 sample crystallized after (a) 6, (b) 12, (c) 24, (d) 27, (e) 30, (f) 36, (g) 48 h, (h) $72 \mathrm{~h}$, respectively. 

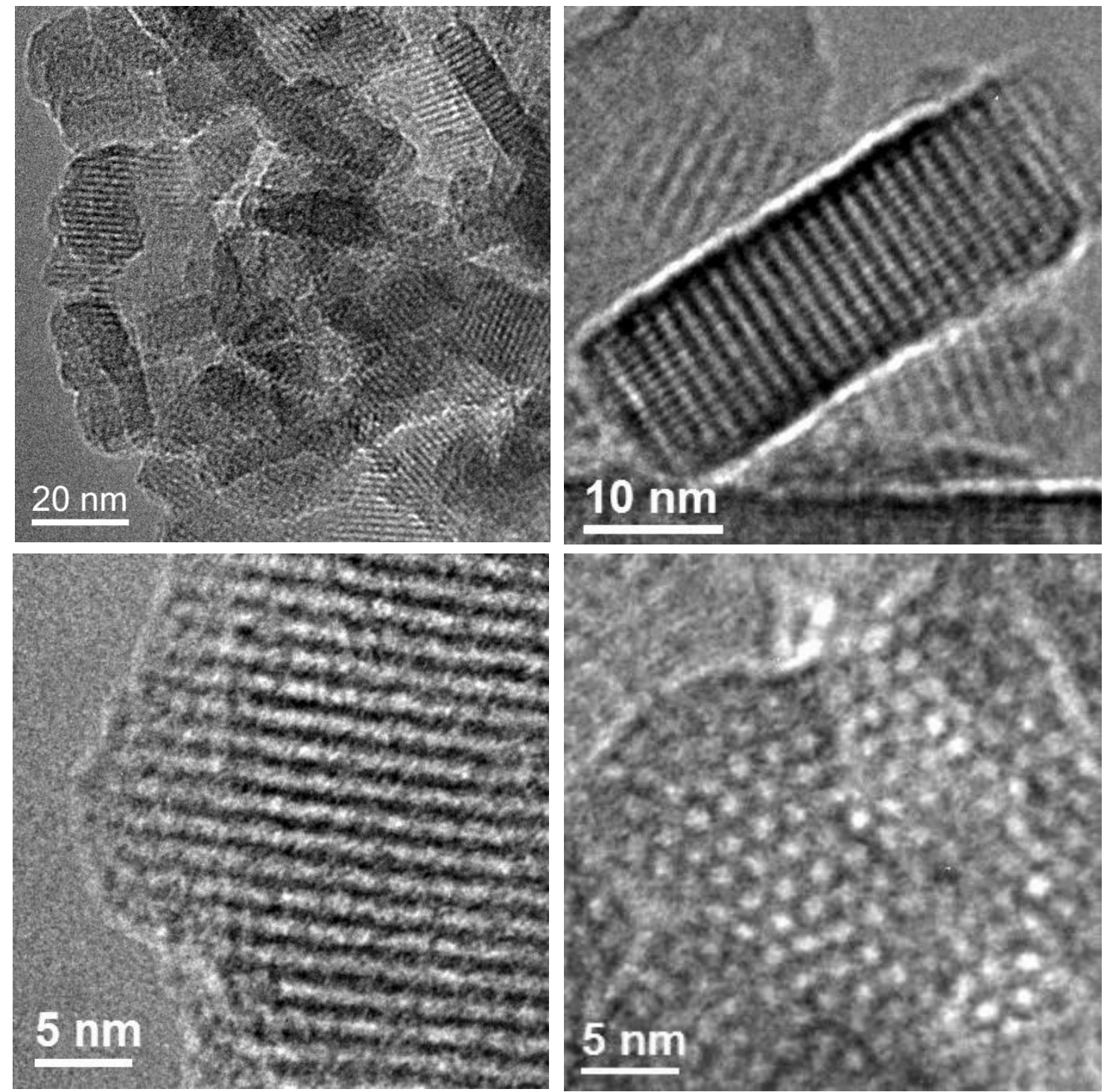

Figure S4. HRTEM images of as-synthesized Nano L-30 sample. 

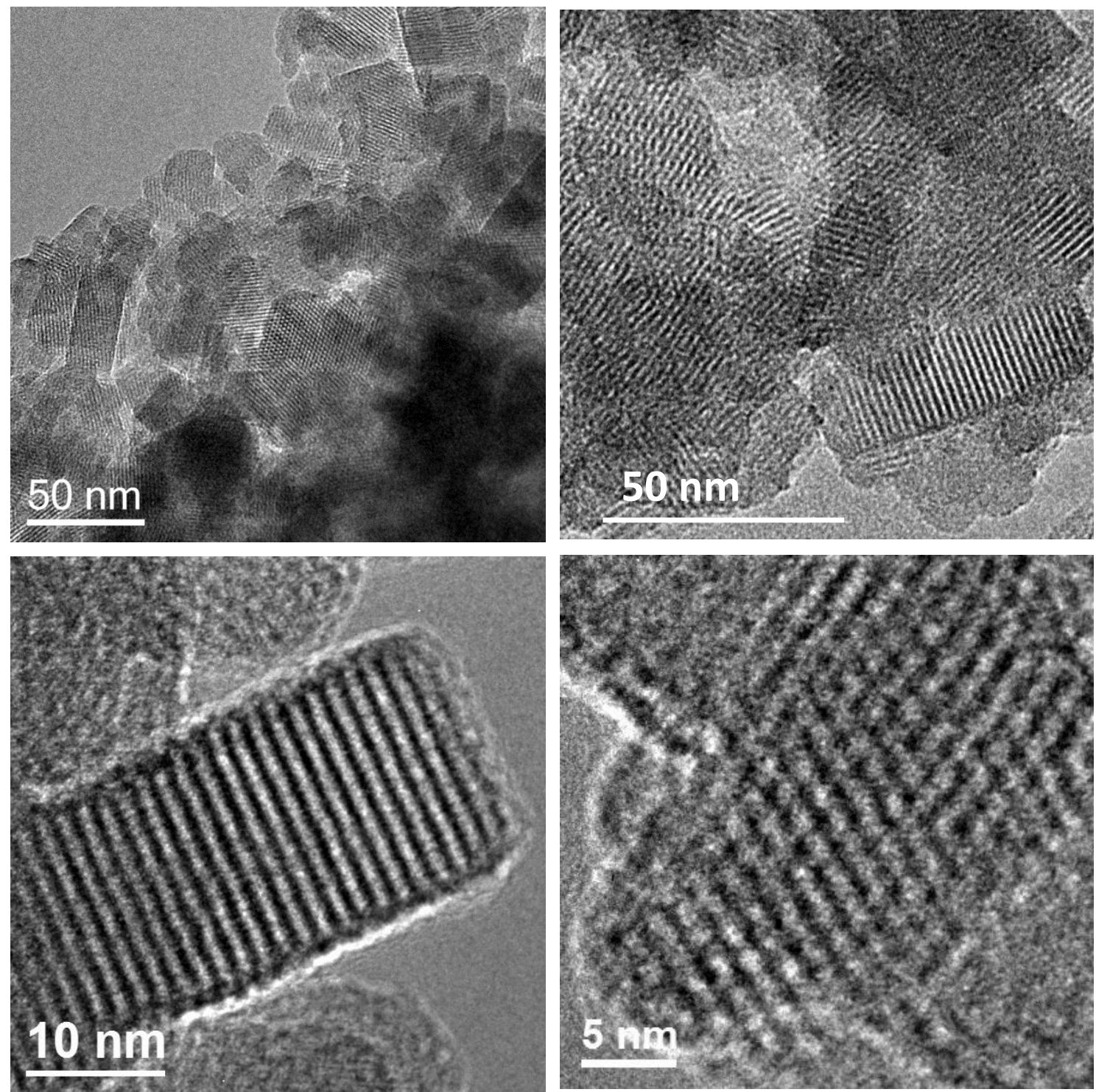

Figure S5. HRTEM images of as-synthesized Nano L-40 sample. 

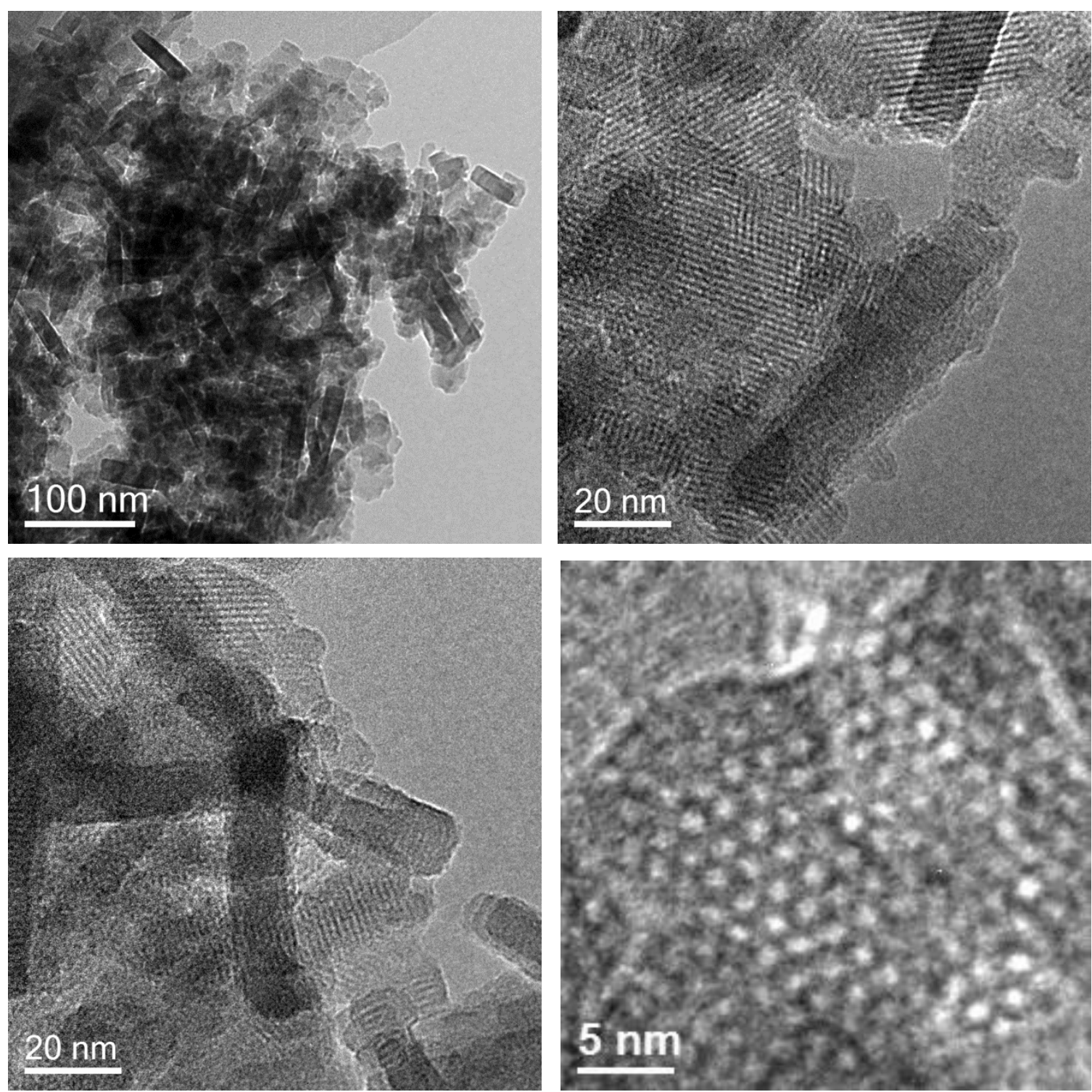

Figure S6. HRTEM images of as-synthesized Nano L-60 sample. 

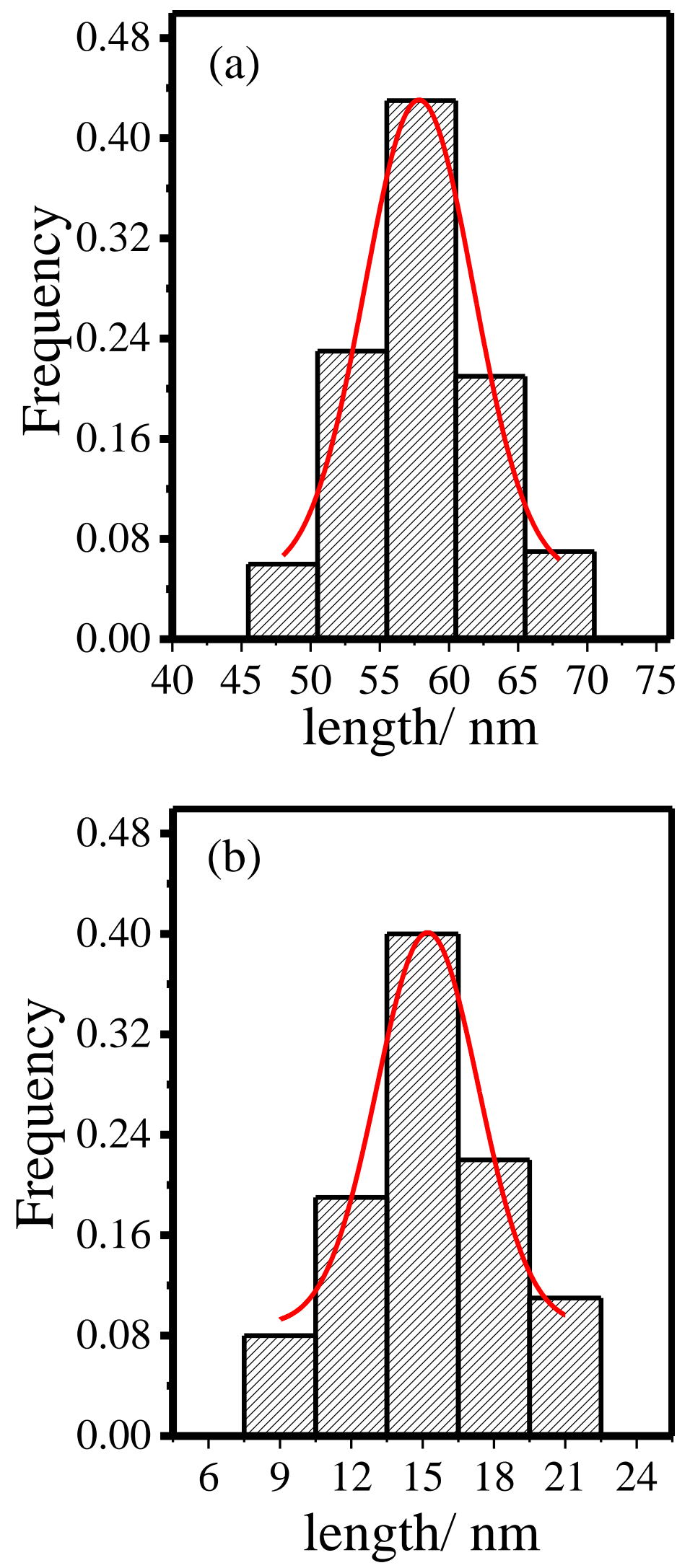

Figure S7. The distance distribution of (a) [100] direction and (b) [001] direction of Nano L-60 sample. 

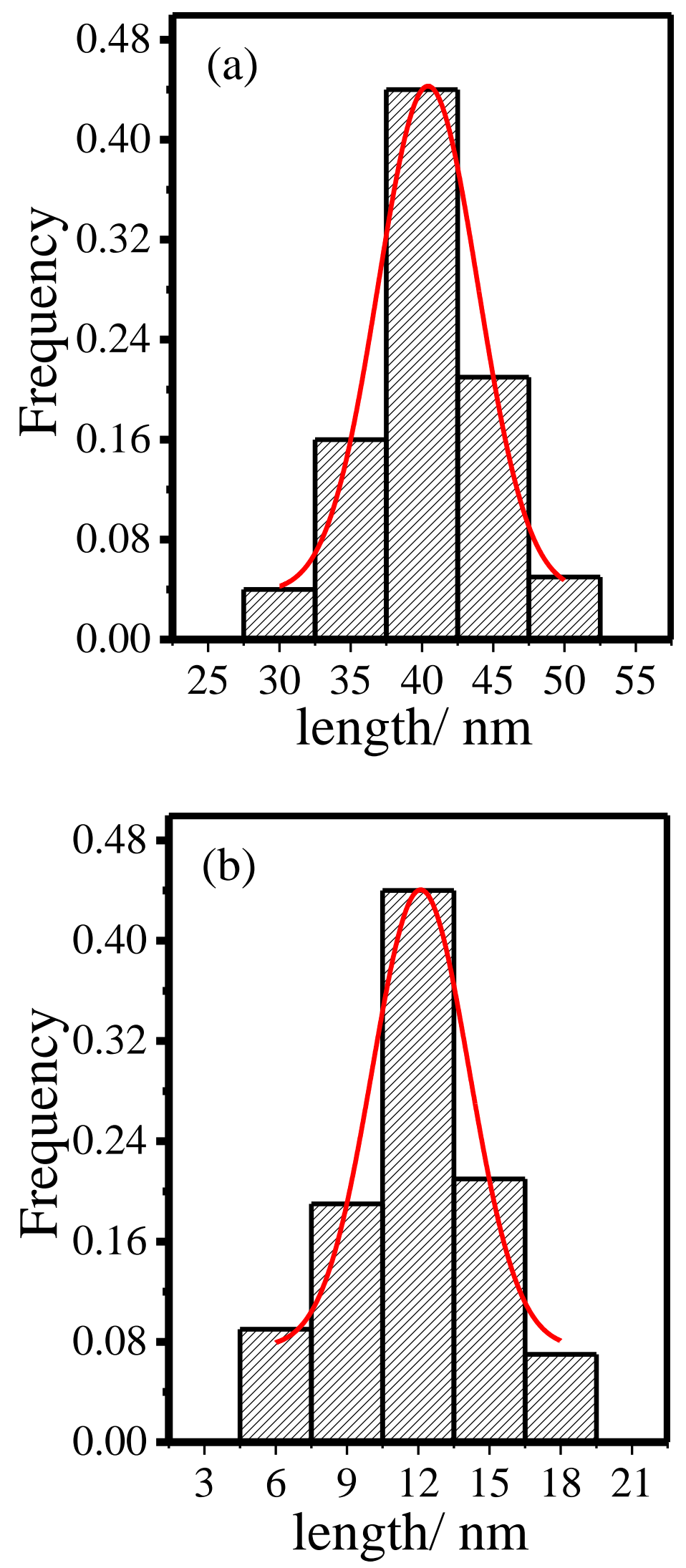

Figure S8. The distance distribution of (a) [100] direction and (b) [001] direction of Nano L-40 sample. 

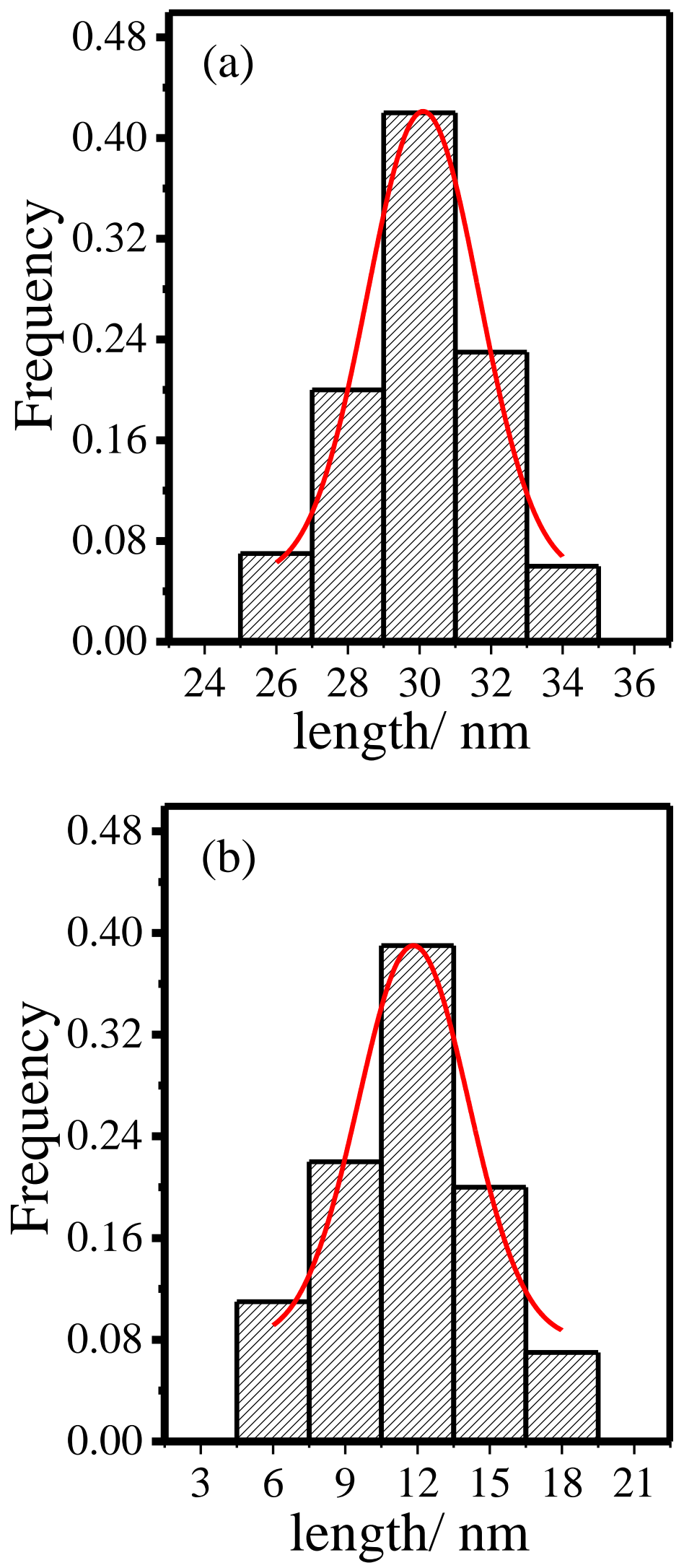

Figure S9. The distance distribution of (a) [100] direction and (b) [001] direction of Nano L-30 sample. 


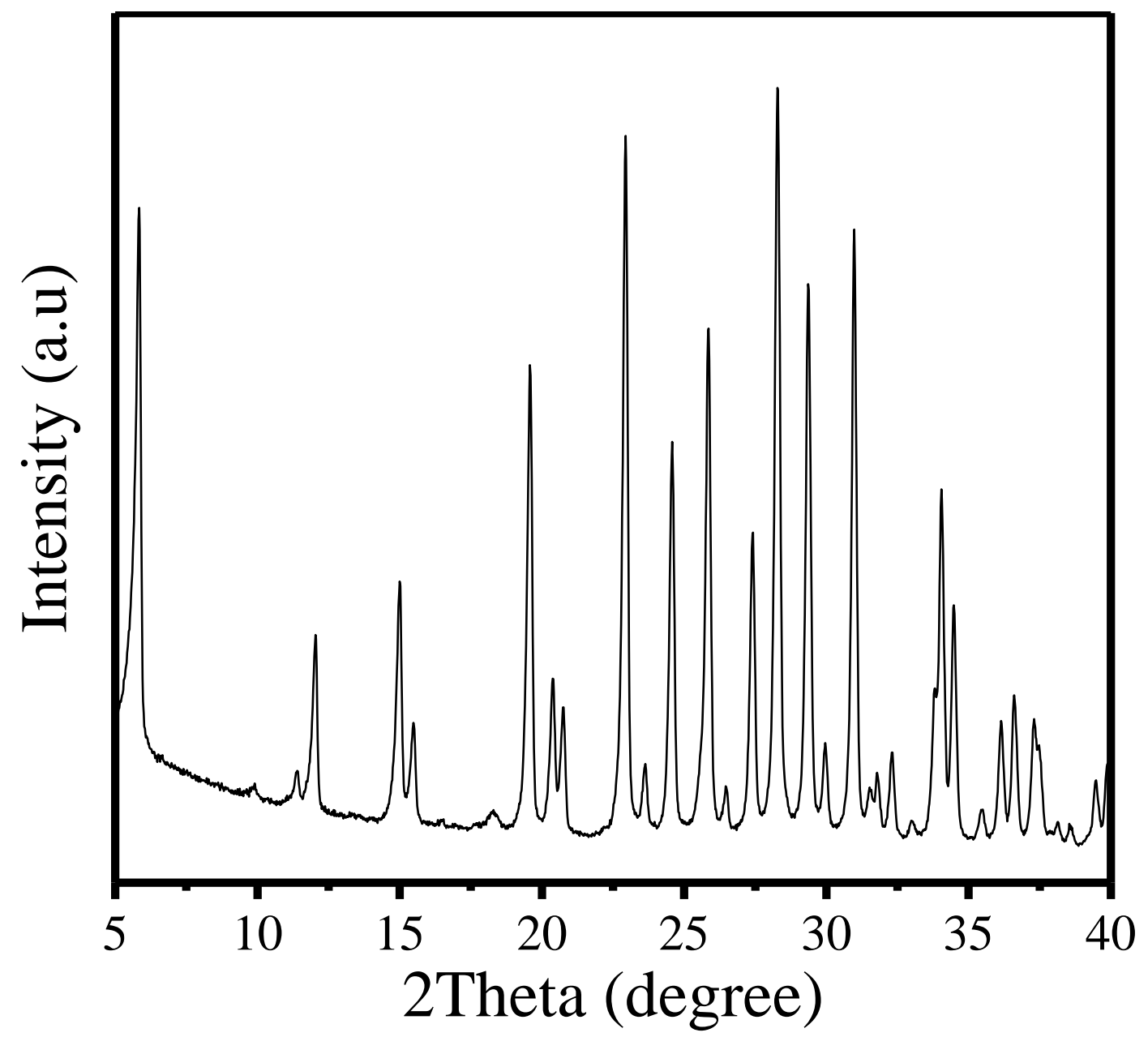

Figure S10. XRD pattern of as-synthesized conventional bulky L sample. 


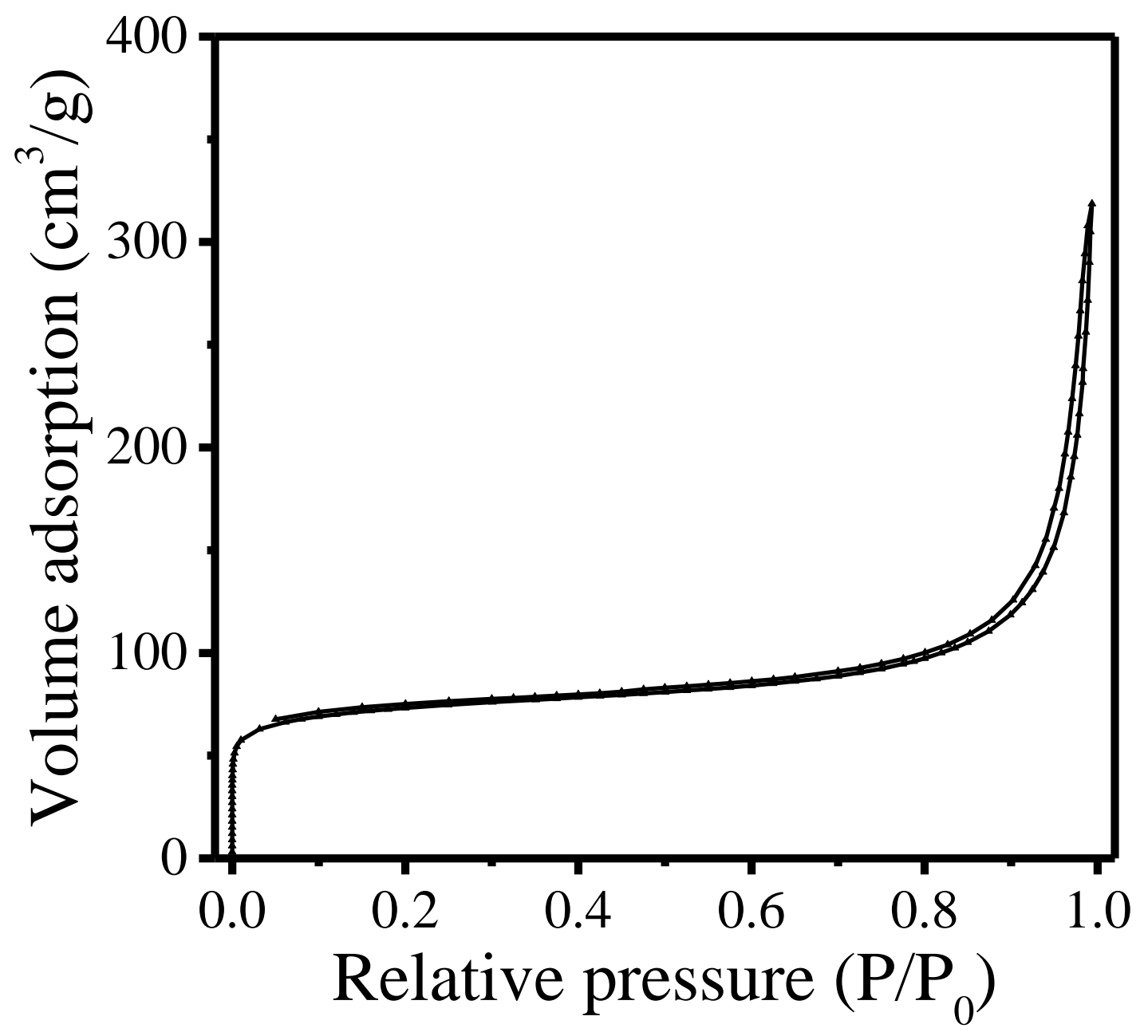

Figure S11. $\mathrm{N}_{2}$ sorption isotherms of $\mathrm{H}$-form conventional bulky L sample. 

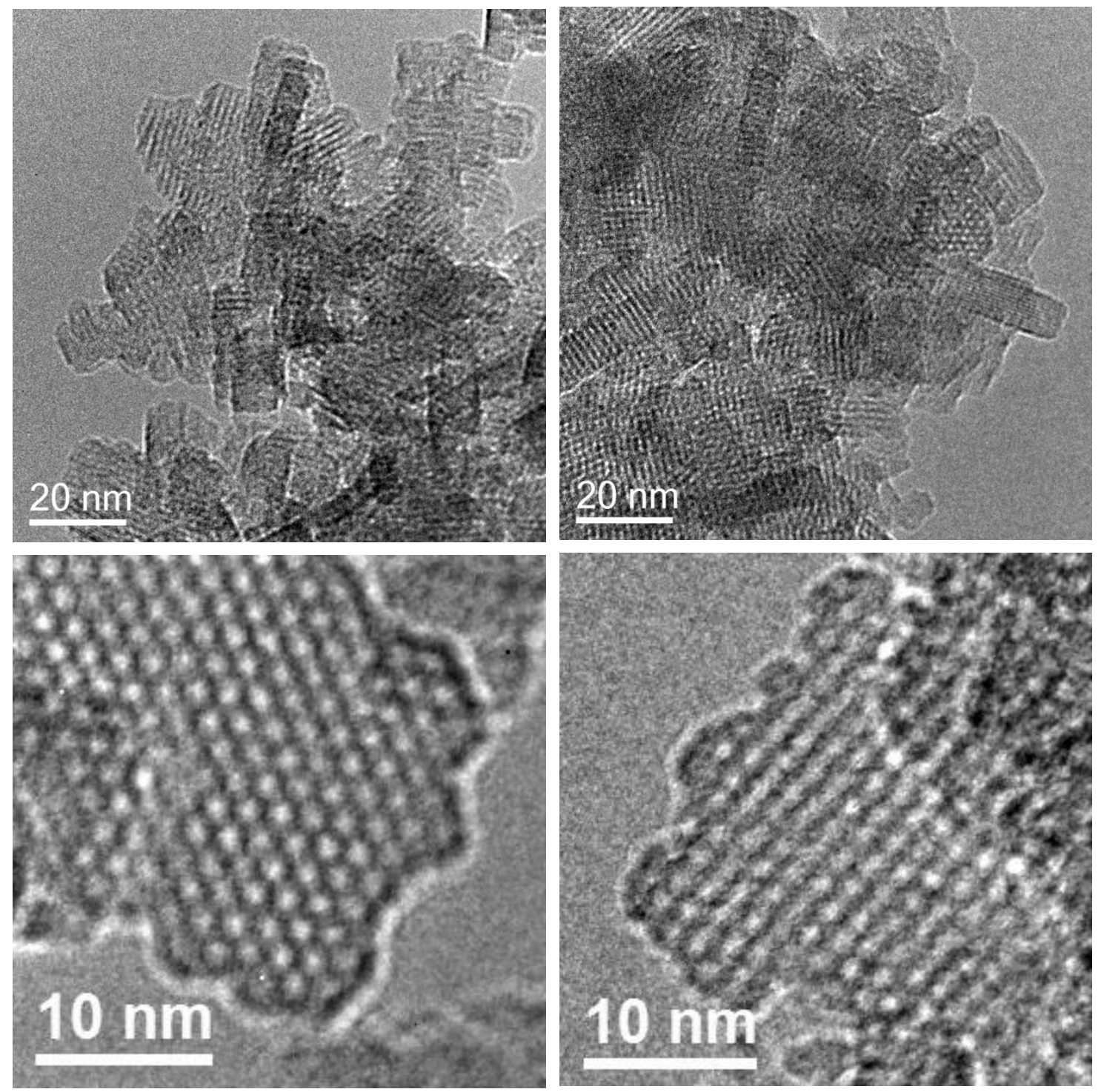

Figure S12. HRTEM images of as-synthesized Nano L-20 sample. 

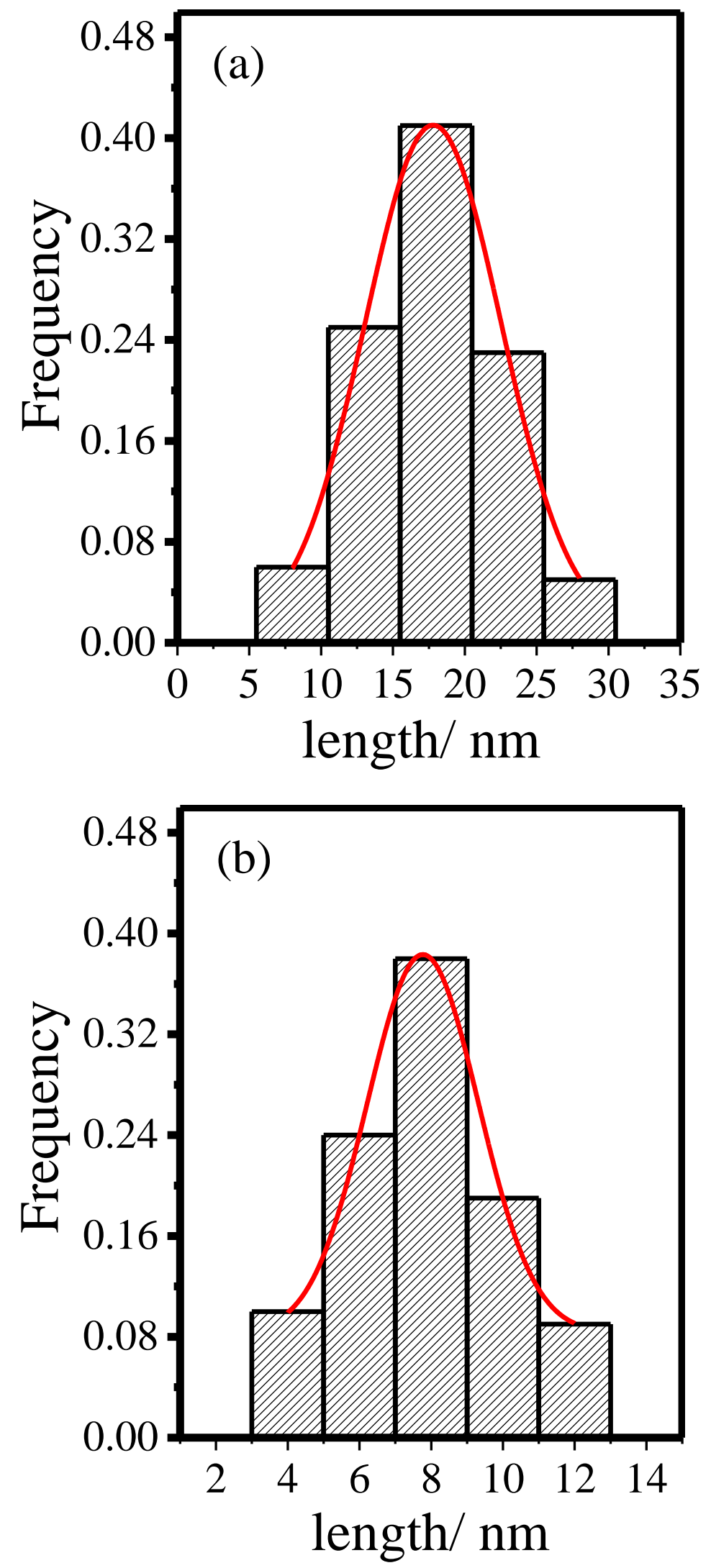

Figure S13. The distance distribution of (a) [100] direction and (b) [001] direction of Nano L-20 sample. 


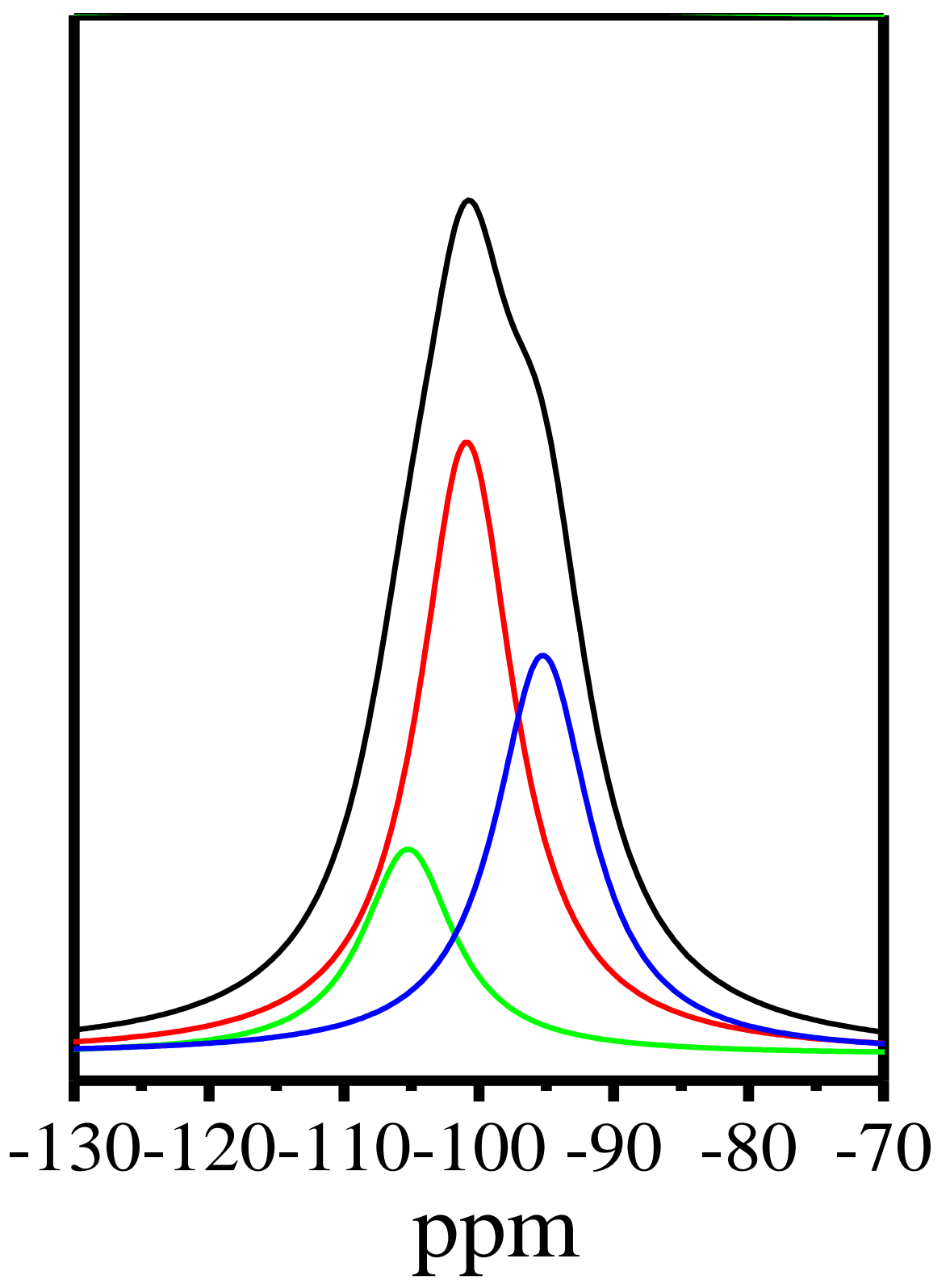

Figure S14. ${ }^{29} \mathrm{Si}$ MAS NMR spectra of as-synthesized conventional bulky L sample. 


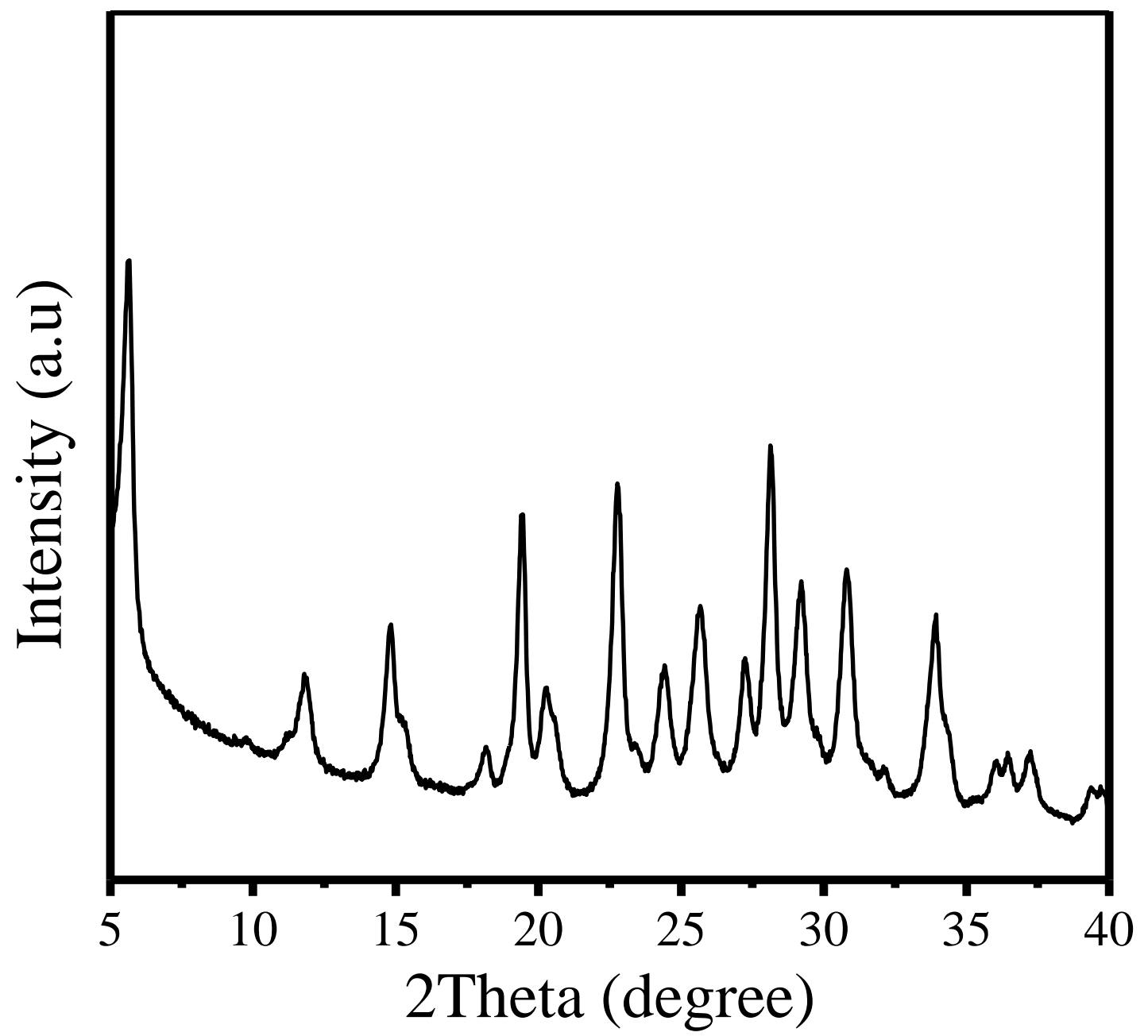

Figure S15. XRD pattern of as-synthesized Nano L-100 sample. 


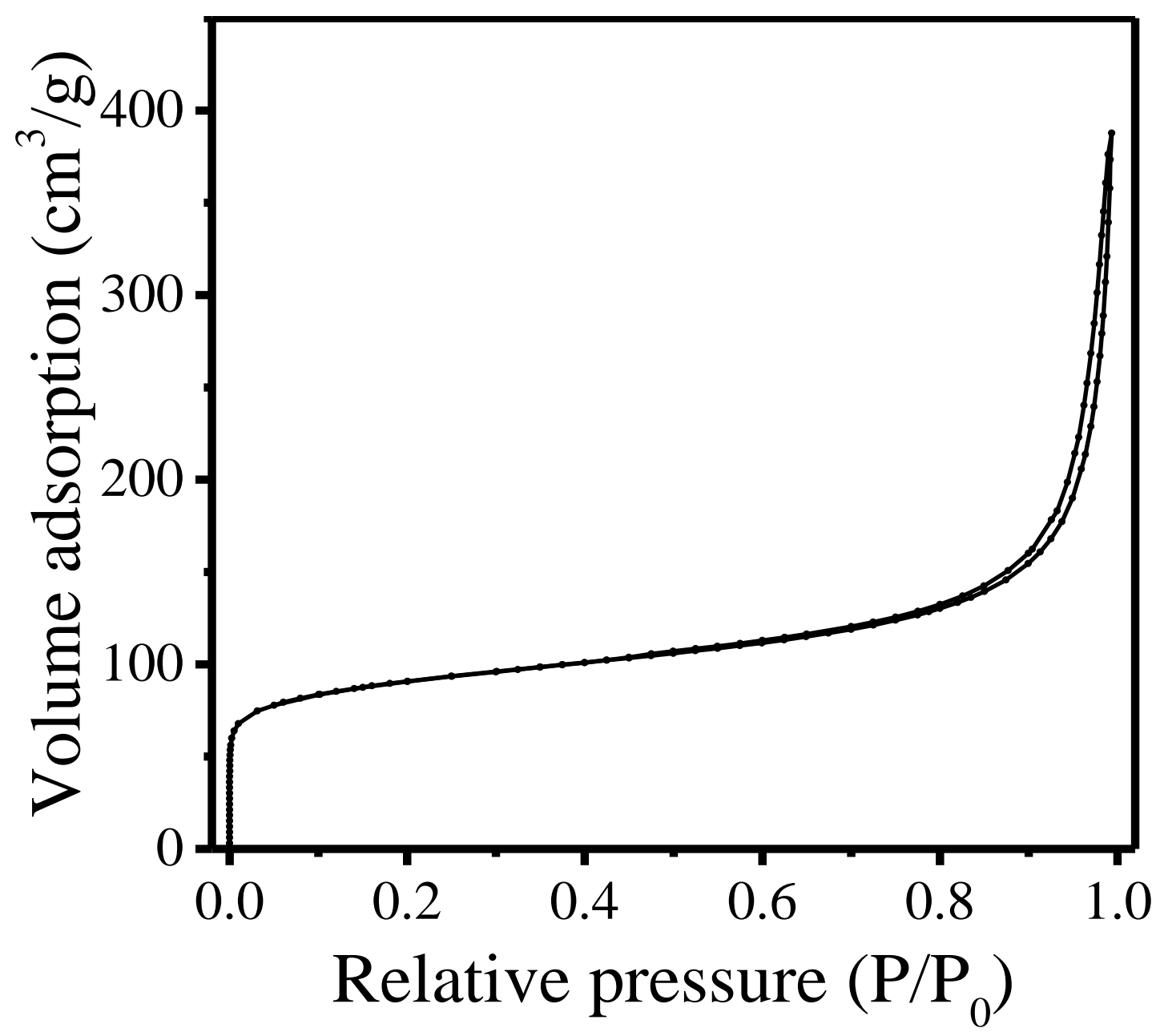

Figure S16. $\mathrm{N}_{2}$ sorption isotherms of $\mathrm{H}$-form Nano L-100 sample. 

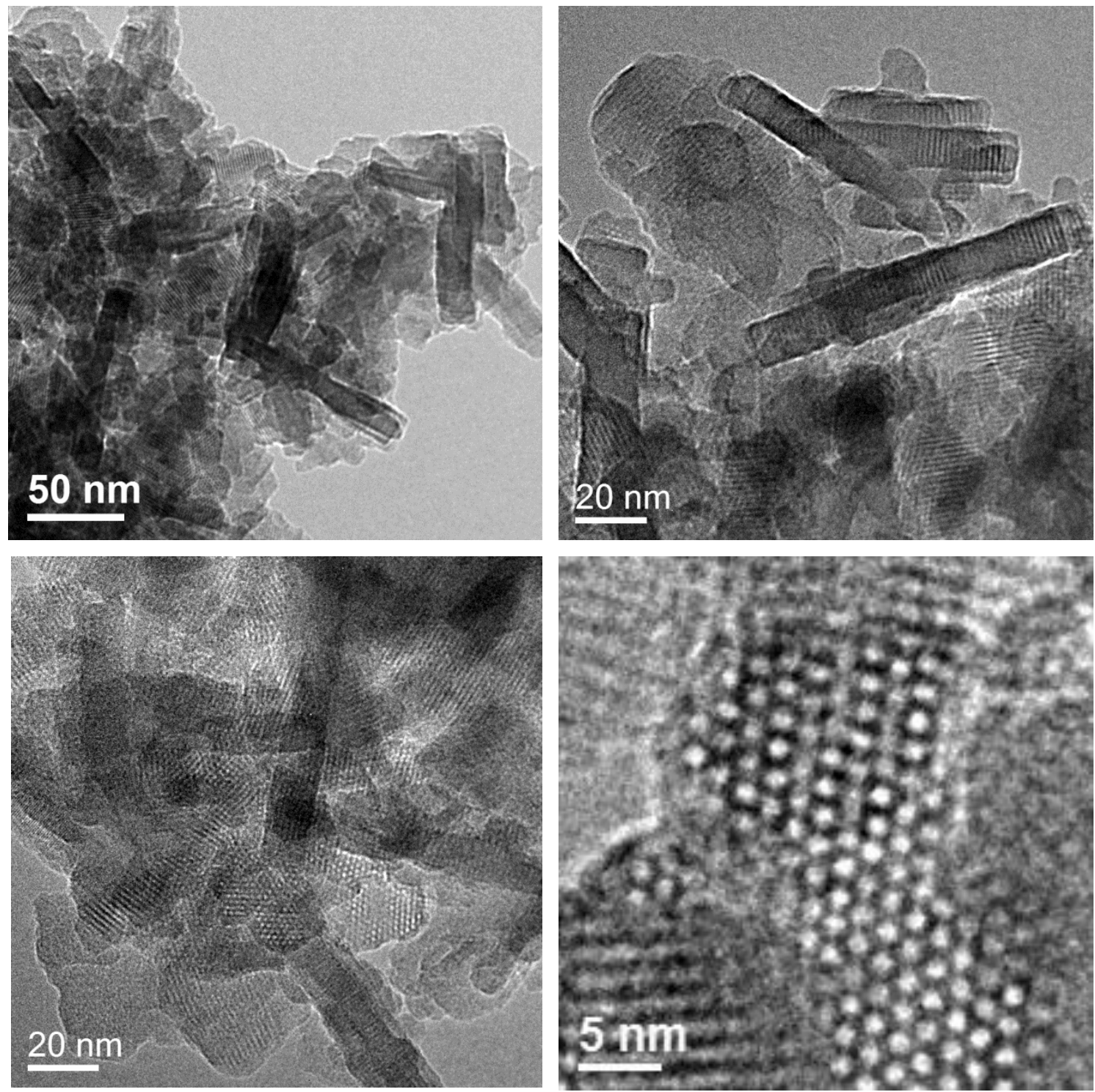

Figure S17. HRTEM images of as-synthesized Nano L-100 sample. 

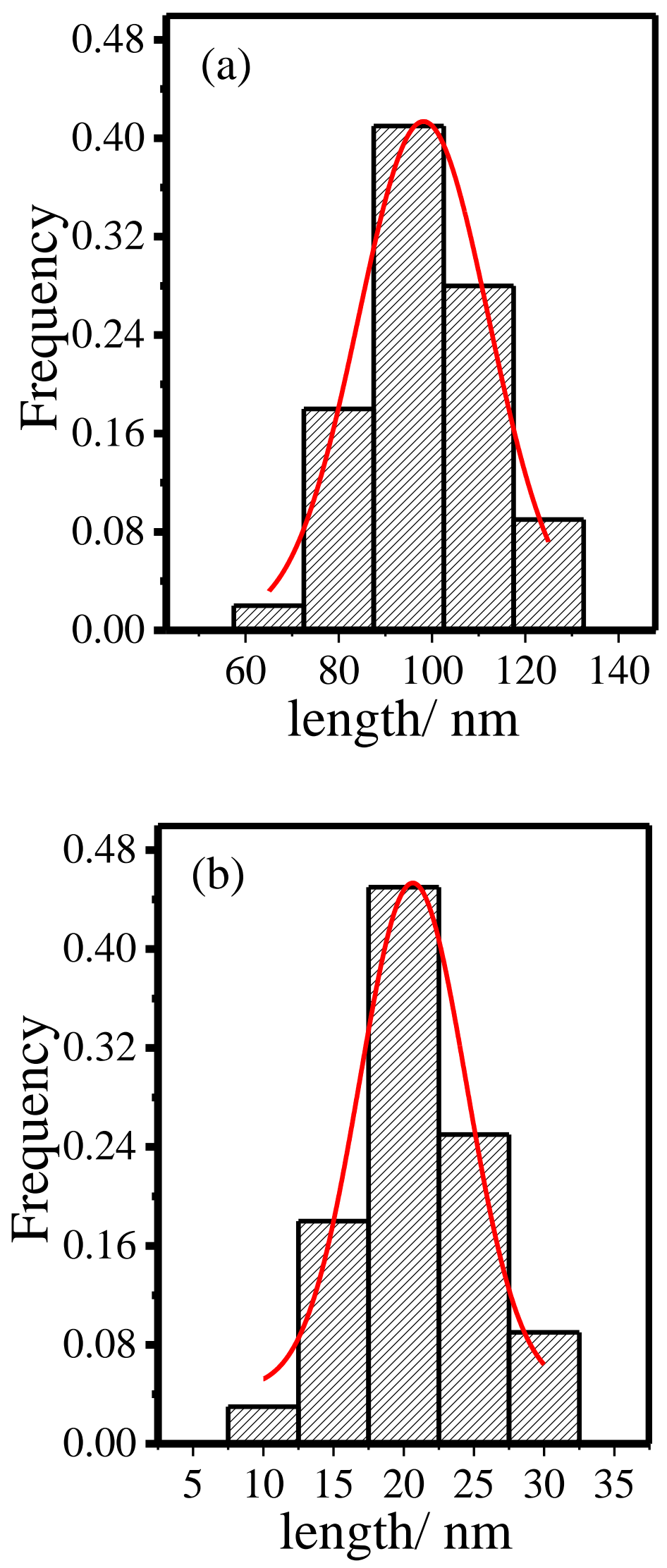

Figure S18. The distance distribution of (a) [100] direction and (b) [001] direction of Nano L-100 sample. 


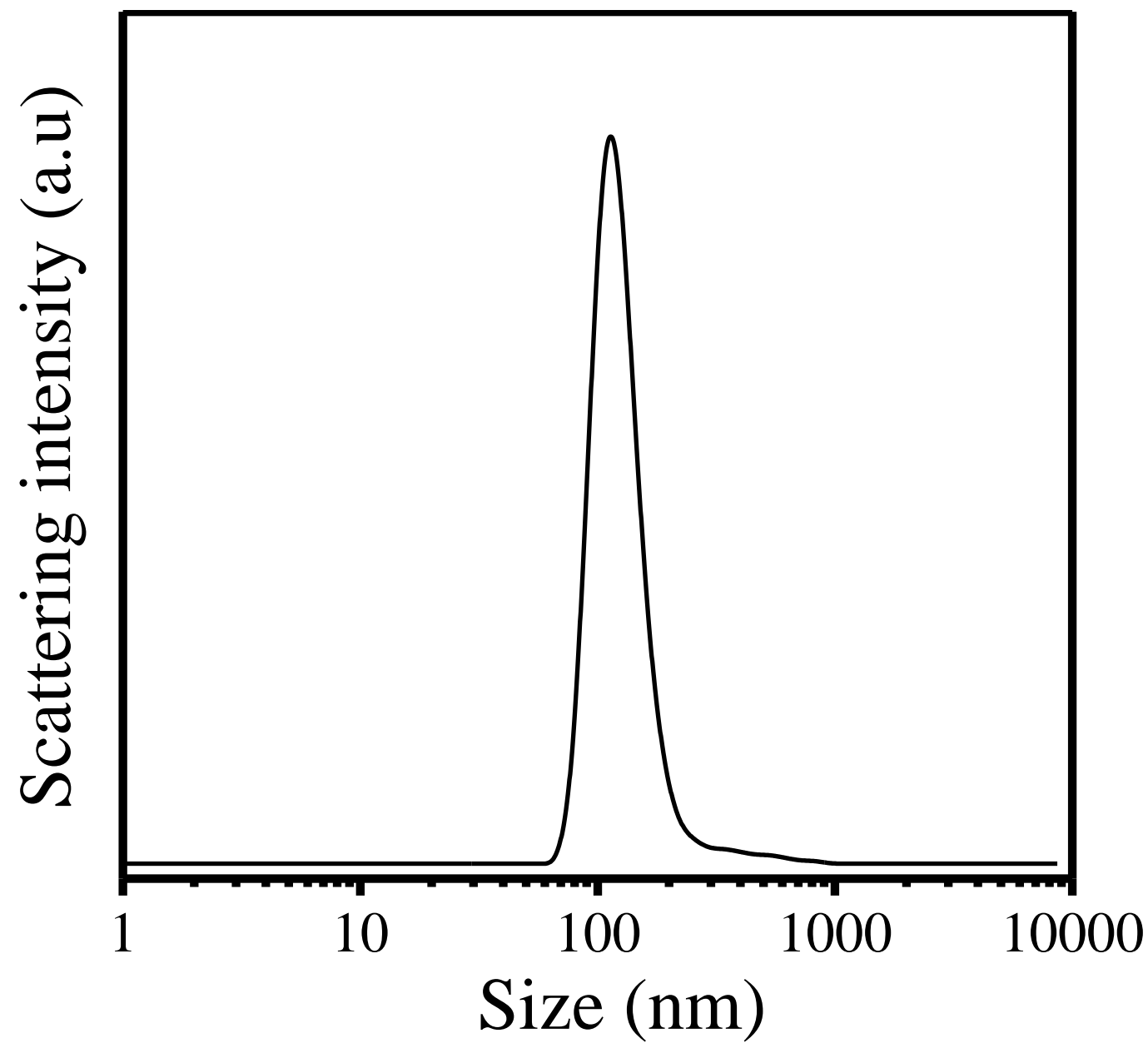

Figure S19. DLS curve of as-synthesized Nano L-100 sample. 


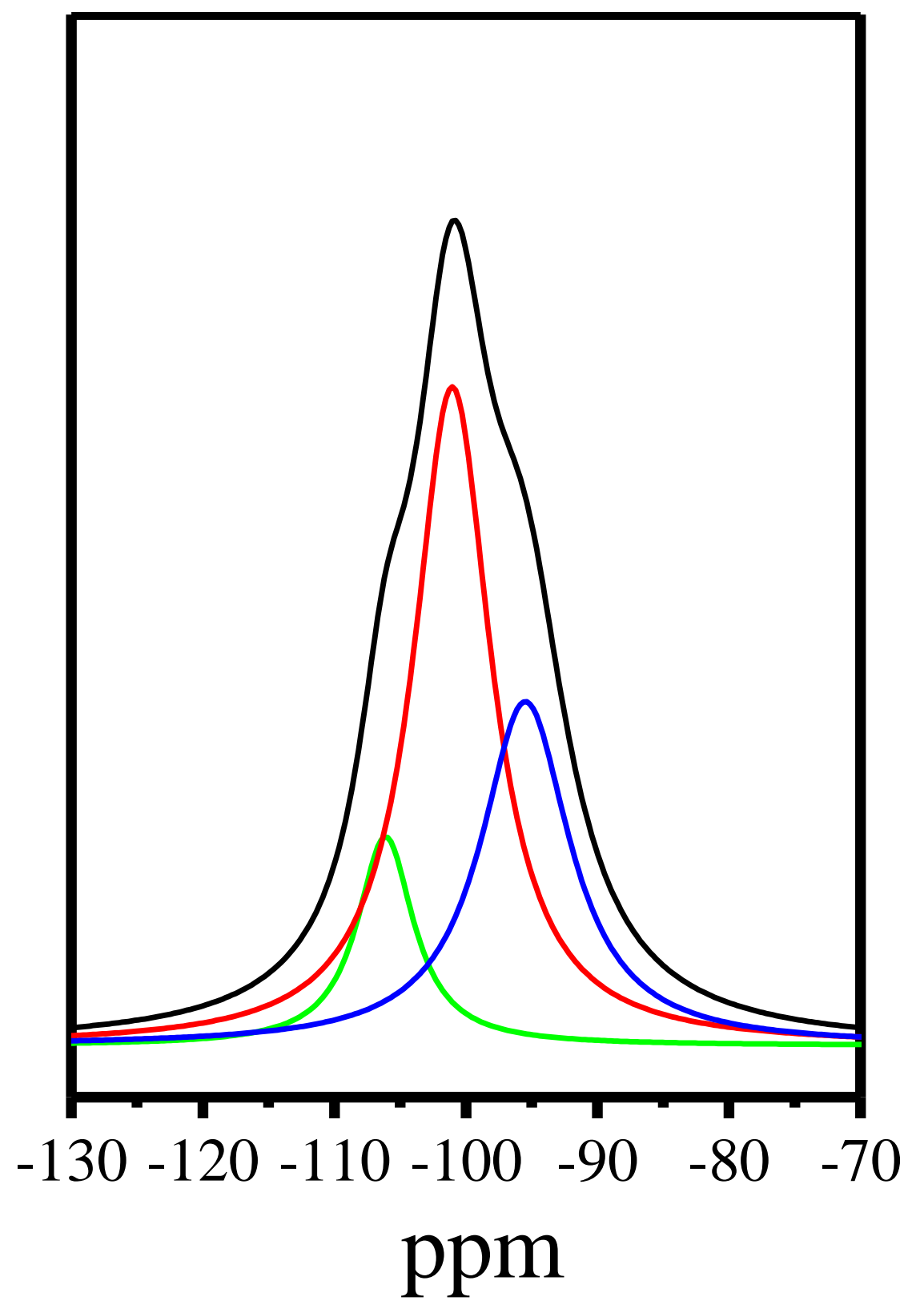

Figure S20. ${ }^{29}$ Si MAS NMR spectra of as-synthesized Nano L-100 sample. 

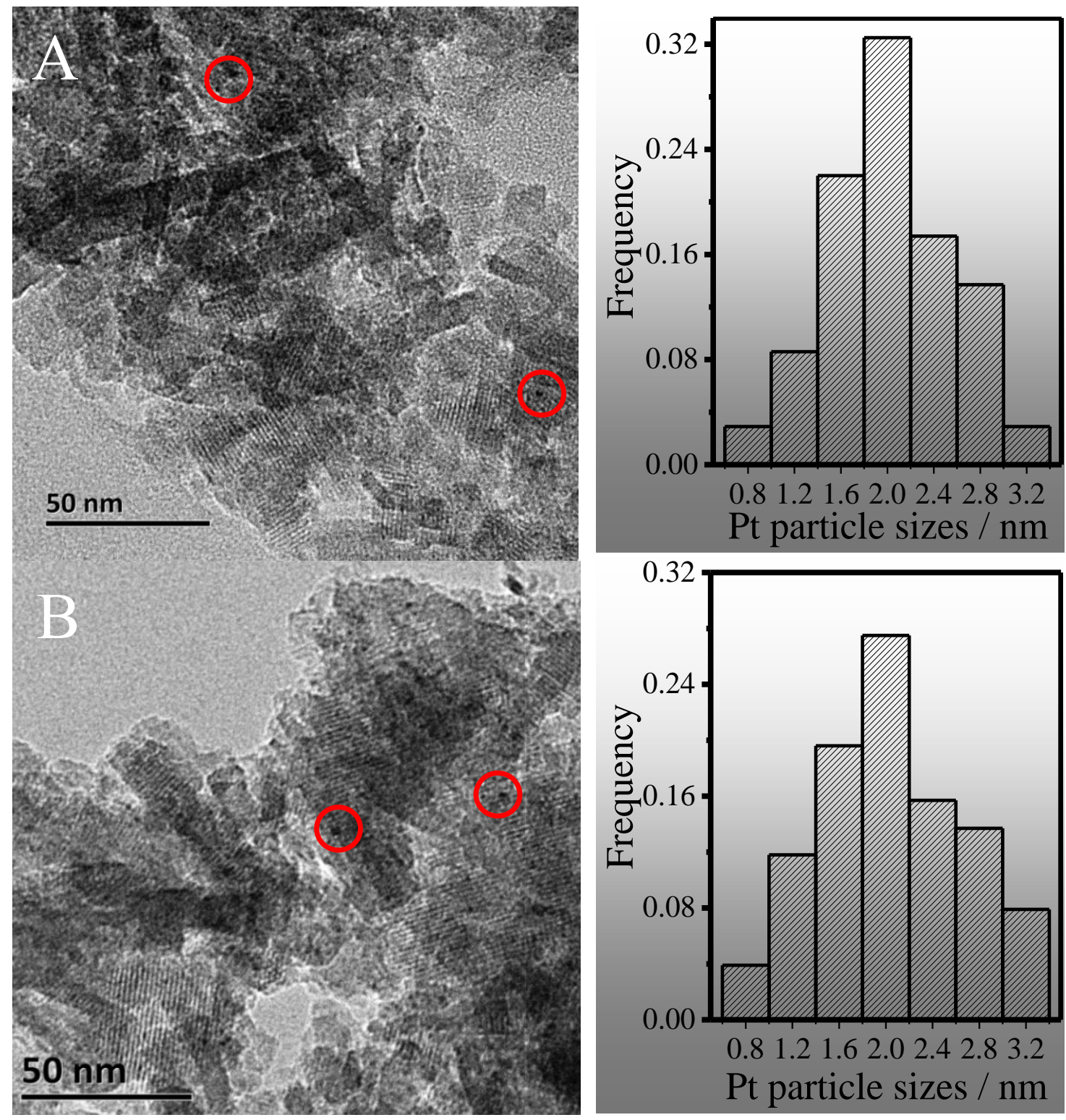

Figure S21. HRTEM images and Pt size distribution of Pt/Nano

L-20 catalyst (A)before reaction and (B) after reaction. 

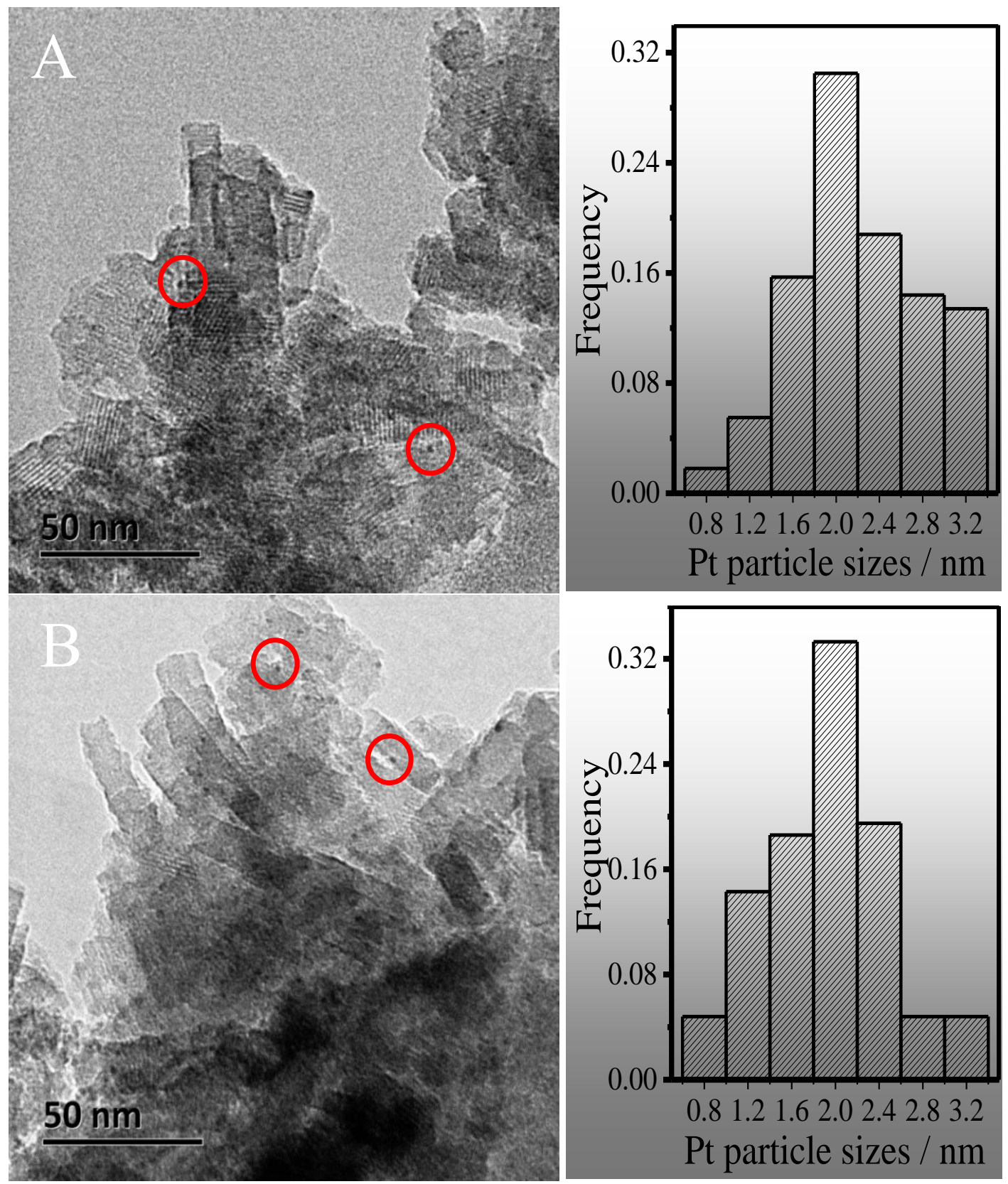

Figure S22. HRTEM images and $\mathrm{Pt}$ size distribution of $\mathrm{Pt} / \mathrm{Nano}$

L-100 catalyst (A) before reaction and (B) after reaction. 


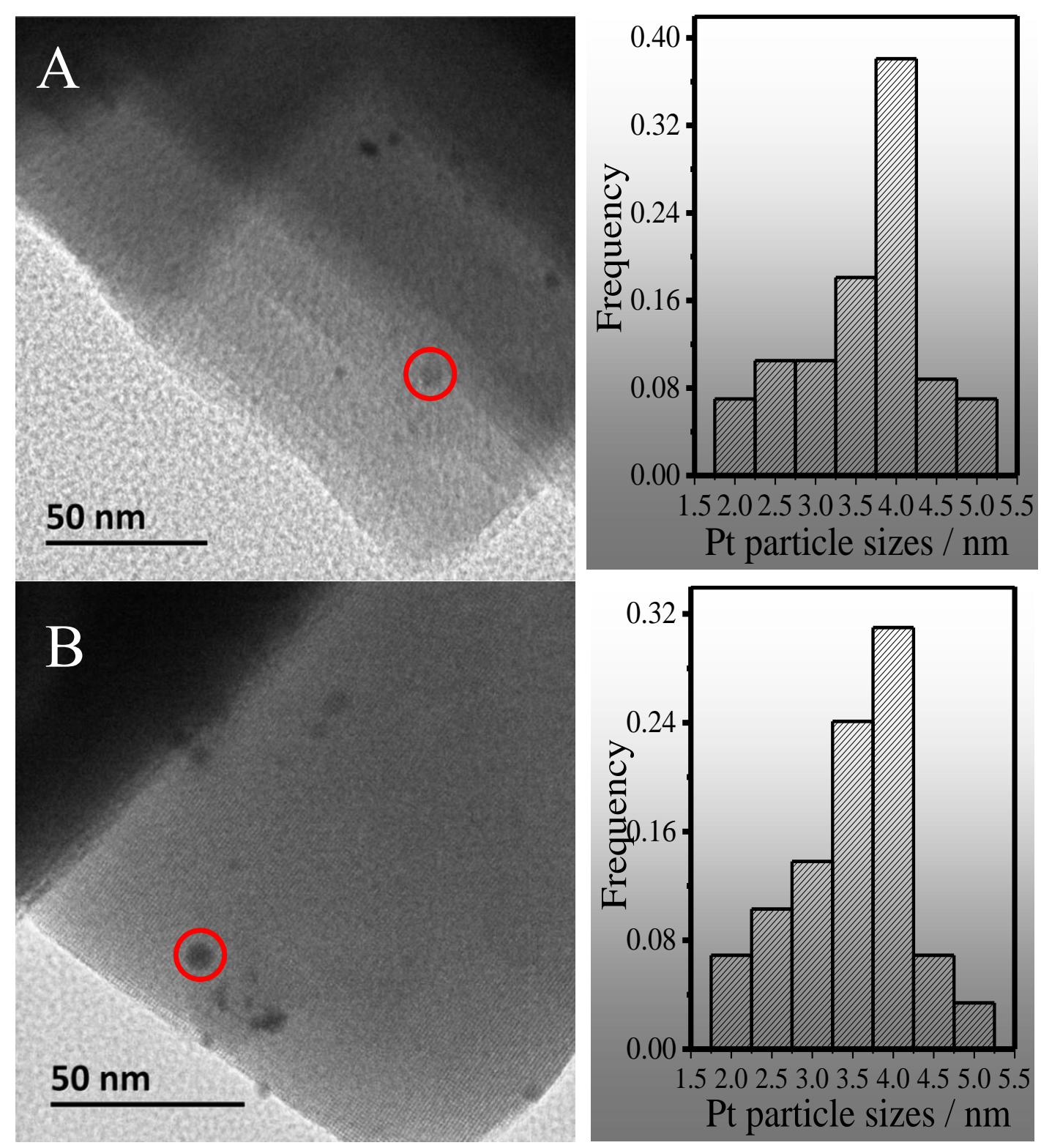

Figure S23. HRTEM images and Pt size distribution of Pt/Conventional bulky L catalyst (A) before reaction and (B) after reaction. 

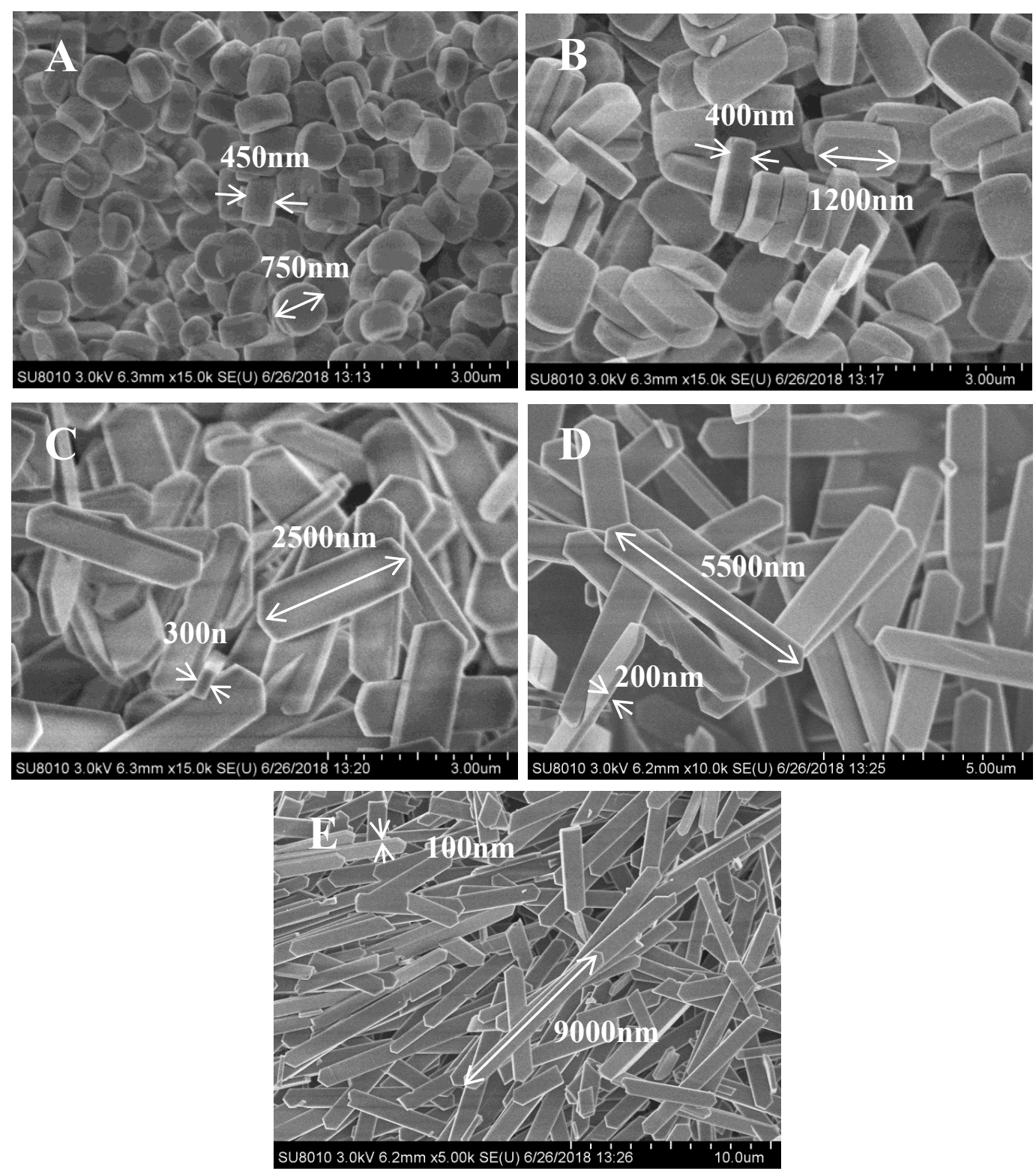

Figure S24. SEM images of MFI zeolite crystals with TPAOH/SiO 2 at (a) 0.95, (b) 0.88, (c) 0.81, (d) 0.73, and (e) 0.65 under the guidance of theoretical prediction. 

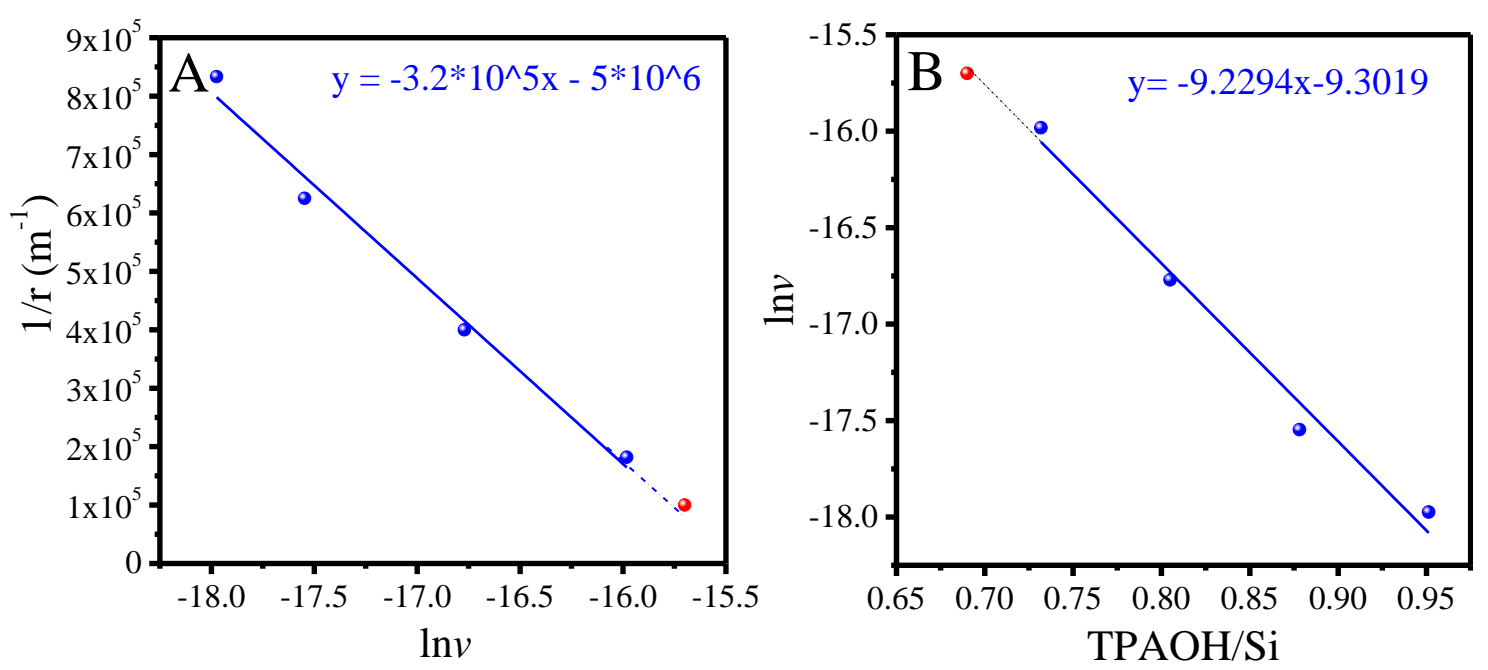

Figure S25. (A) Theoretical crystallization rates of MFI zeolite calculated from the equation, (B) dependence of $\ln v$ on the ratio of $\mathrm{TPAOH} / \mathrm{SiO}_{2}$ in the starting gels. 


\section{References}

1. Johnson, E. R.; Becke, A. D. A post-hartree-fock model of intermolecular interactions: inclusion of higher-order corrections. J. Chem. Phys. 2006, 124, 174104.

2. Perdew, J. P.; Burke, K.; Ernzerhof, M. Generalized gradient approximation made simple. Phys. Rev. Lett. 1996, 77, 3865-3868.

3. Perdew, J. P.; Wang, Y. Accurate and Simple Analytic Representation of the Electron-Gas Correlation-Energy. Phys. Rev. B 1992, 45, 13244-13249.

4. Grimme, S.; Ehrlich, S.; Goerigk, L. Effect of the Damping Function in Dispersion Corrected Density Functional Theory. J. Comp. Chem. 2011, 32, 1456-1465.

5. Ghysels, A.; Verstraelen, T.; Hemelsoet, K.; Waroquier, M.; Speybroeck, V. TAMkin: a versatile package for vibrational analysis and chemical kinetics. J. Chem. Inf. Model. 2010, 50, 1736-1750.

6. Moteki, T.; Chaikittisilp, W.; Sakamoto, Y.; Shimojima, A.; Okubo, T. Role of acidic pretreatment of layered silicate RUB-15 in its topotactic conversion into pure silica sodalite. Chem. Mater. 2011, 23, 3564-3570. 